\title{
Affordable Care Act Medicaid Expansions and the Impact on Nurses*
}

\author{
Michael DiNardi \\ University of Connecticut \\ Draft: November 2017 \\ Click for newest version \\ Preliminary and Incomplete: Please do not cite
}

\begin{abstract}
:
Shortages in healthcare labor markets and decreases in quality of care were major concerns voiced by critics of the 2010 Patient Protection and Affordable Care Act. I use the 2014 expansions in Medicaid coverage as a plausibly exogenous increase in the demand for nurses to estimate the effects on nurse labor market outcomes and quality of care measures. Using a difference-in-differences strategy, I find the 2014 Medicaid expansions increased nurses' hours worked per week by 1.5 percent ( 0.55 hours). Increases in hours worked are larger for rural nurses, likely due to larger increases in insurance coverage in rural areas from the Medicaid expansions. In disaggregated analyses, employment of licensed practical nurses increased by 15 percent, but I do not find any statistically significant effects on registered nurse employment. Hours worked per week increased by 2.4 percent ( 0.89 hours) for licensed practical nurses and by 1.2 percent for registered nurses ( 0.46 hours). I do not find any consistent negative effects on quality of care as measured by patient ratings of nursing care and hospital-acquired infection rates.
\end{abstract}

JEL Classification: I13, I18, J23

KEY WORDS: Affordable Care Act, Medicaid, nurses

* Department of Economics, University of Connecticut, 365 Fairfield Way, U-1063, Storrs, Connecticut, 06269. E-mail: michael.dinardi@uconn.edu. 


\section{Introduction}

One of the major components of the 2010 Patient Protection and Affordable Care Act (ACA) was the expansion of Medicaid to individuals with income less than 138 percent of the federal poverty line with the goal of increasing insurance coverage and access to health care among low-income individuals. By March 2016, over 11 million newly-eligible adults in expansions states were enrolled in Medicaid, accounting for over 15 percent of all Medicaid enrollees in the United States. ${ }^{1}$ Critics of the ACA argued such in an increase in health insurance coverage would create and worsen current shortages in the healthcare workforce due to increased demand from the newly insured population and reduce the quality of care (Cunningham, 2013; Anderson, 2014).

While this argument largely focused on physicians, the nurse labor market faces significant shortages (Buerhaus, Auerbach, and Staiger, 2009; U.S. Department of Health and Human Services, 2014), and nurses are the principal providers of direct care to patients. Nurses are also the largest healthcare occupation in the United States, with 3.4 million employed licensed nurses comprising 30 percent of all healthcare occupations in $2014 .^{2}$ Because of their large role in the provision of healthcare services, nurses and nursing care are likely to be affected by an increase in demand for healthcare services from the ACA Medicaid expansions. In this paper, I explore how the ACA Medicaid expansions affected nurse labor market outcomes and quality of nursing care.

\footnotetext{
${ }^{1}$ This estimate excludes Medicaid enrollments in U.S. territories and excludes North Dakota because enrollment data is not available. Author's calculations from U.S. Centers for Medicare and Medicaid Services Medicaid Budget and Expenditure System March 2016 enrollment report. https://www.medicaid.gov/medicaid/programinformation/downloads/cms-64-enrollment-report-jan-mar-2016.pdf. Accessed June 16, 2017.

${ }^{2}$ Author's calculations from the U.S. Bureau of Labor Statistics May 2014 Occupational Employment Statistics estimates.
} 
This paper contributes to three strands of literature. First, I add to the growing literature on effects of the ACA Medicaid expansions by focusing on the effects on nurses, a major input in the production of healthcare services. Prior research shows the ACA Medicaid expansions increased health insurance coverage among low-income adults (Courtemanche et al., 2017; Simon, Soni, and Cawley, 2017; Soni, Hendryx, and Simon, 2017; Wherry and Miller, 2016) and low-educated adults (Kaestner et al., 2017; Gooptu, et al., 2016). Insurance coverage under the ACA Medicaid expansions also led to increases in access to care, healthcare utilization, and Medicaid discharges (Anderson et al., 2016; Kaufman et al. 2016; Shartzer, Long, and Anderson, 2016; Wherry and Miller, 2016; Simon, Soni, and Cawley, 2017). Research on the ACA Medicaid expansions has also explored effects on prescription drug use (Ghosh, Sommers, and Simon, 2017), labor supply (Kaestner, et al., 2017), job-lock (Leung and Mas, 2016), and financial well-being (Hu et al., 2016). Despite the large amount of work on the ACA Medicaid expansions in these areas, little is known about its effects on the healthcare workforce.

Second, I add to the literature on the relationship between nurse staffing levels and skill mix on patient outcomes by estimating impacts of the ACA Medicaid expansions on patient ratings of nursing care and hospital-acquired infection rates. Decreases in nurse staffing and skill-mix are negatively associated with adverse patient outcomes such as hospital-acquired infections and mortality (Aiken, et al., 2002; Aiken et al., 2003; Needleman, et al., 2002; Rogers et al., 2004; Scott et al., 2006; Olds and Clarke, 2010; Needleman, et al., 2011), but other studies that attempt to estimate causal effects are less clear about this link. Evans and Kim (2006) find some evidence of higher mortality among patients admitted when patient-to-nurse ratios are high, although the effects are small and not robust to alternative specifications. Using California's mandated minimum nurse-patient staffing levels, Cook, et al. (2012) find the law 
increased nurse-patient ratios in hospitals with ratios lower than the mandate prior to the change, but do not find a causal effect on patient outcomes. Gruber and Kleiner (2012) find nurse strikes increase inpatient mortality and 30-day readmission rates that could be driven by decreases in nurse staffing and quality. To my knowledge, one paper has examined the relationship between the ACA Medicaid expansions and patient outcomes, finding no change in in-hospital mortality or length of stay (Anderson et al., 2016).

I use the ACA Medicaid expansions as a plausibly exogenous increase in demand for nurses to estimate the effects on nurse labor market outcomes. Overall, the 2014 ACA Medicaid expansions increased nurses' hours worked per weekly 1.5 percent ( 0.55 hours) and increased the probability of working at least 35 hours a week by 4 percentage points. I find the increase in hours worked per week by nurses was greater in rural areas (4.4 percent, 1.64 hours) than in urban areas (1.1 percent, 0.39 hours), and this is consistent with larger increases in insurance take-up and utilization of healthcare services in rural areas (Kaufman et al., 2016; Soni, Hendryx, and Simon, 2017). There are also occupation-specific differences in nurse labor market outcomes. For licensed practical nurses (LPNs), the ACA Medicaid expansions increased employment by 15 percent and hours worked per week by 2.4 percent ( 0.89 hours), but had no statistically significant effect on their wages. Hours worked per week by registered nurses (RNs) increased by 0.53 hours, but I do not find statistically significant effects on RNs' employment or wages. These differences may be explained by an increase in demand for relatively basic nursing care that LPNs are able to provide at a lower cost relative to RNs and supply constraints of RNs due to higher educational requirements. My results imply the 2014 ACA Medicaid expansions led to small average increases in demand for nurses. 
I also study the association between the 2014 ACA Medicaid expansions and quality of care which has been linked to changes in nurse staffing. Decreases in quality of care can result in significant costs. For example, the annual direct costs of hospital-acquired infections are estimated to be as high as $\$ 52$ billion, $^{3}$ and approximately 1.7 million hospital-acquired infections occur each year, resulting in 99,000 deaths (Klevens et al., 2007). Using data from the U.S. Centers for Medicare and Medicaid Services Hospital Compare archive, I test whether the 2014 ACA Medicaid expansions are associated changes in patient ratings of nursing care and hospital-acquired infection rates. Most estimates are not statistically significant, and, overall, the estimates do not show a consistent decline in quality of care. While these estimates are imprecise, I show that fatigue is an unlikely source of changes in quality as the increase in nurse hours worked was driven by a shift from part-time to full-time work.

\section{Background on the Affordable Care Act Medicaid Expansions}

The ACA was passed in 2010 with the goal of expanding access to healthcare, reducing costs, and increasing quality of care. Under the original plan, states were required to expand Medicaid coverage to all adults with income less than 138 percent of the federal poverty line, but this was struck down by the Supreme Court struck in 2012. Instead, the decision to expand Medicaid was left to each state. ${ }^{4}$ For states that expand Medicaid, the federal government fully funds coverage of newly eligible adults for three years, and the funding gradually phases down to 90 percent by 2020. On January 1, 2014, 25 states expanded Medicaid, and by 2017, a total of 32 states, including Washington D.C., had expanded Medicaid coverage to low-income adults.

\footnotetext{
${ }^{3}$ Original estimate from Scott (2009) inflated to 2016 dollars using the Consumer Price Index.

${ }^{4}$ Details of the U.S. Supreme Court's decision can be found here: http://www.supremecourt.gov/opinions/11pdf/11393c3a2.pdf. Accessed June 16, 2017.
} 


\section{Conceptual Framework}

\subsection{ACA Medicaid expansions and the nurse labor market}

Given the large increase in the population covered by Medicaid due to the ACA expansions, how would this insurance demand shock affect nurses in expansion states? Because insurance reduces the cost of care, this large group of individuals may use their coverage to access healthcare that they otherwise would not have which would increase demand for healthcare services. The increase in demand for healthcare services should result also in a increase in demand for nurses, unless employers are able to provide these services with other healthcare labor or capital inputs.

As a public health insurance option, Medicaid could crowd out private health insurance, thereby dampening the effect on demand for healthcare services and, subsequently, the demand for nurses. Can this case be ruled out? Using my main estimation sample and data from the 20102015 American Community Survey, I estimate effects of the ACA Medicaid expansions on insurance coverage among adults $26-64$ with $\$ 35,000$ in total family income or less. ${ }^{5}$ The results in Panel A of Table 1 show the ACA Medicaid expansions are associated with a 5.9 percentage point increase in any health insurance coverage, an 8.8 percentage point increase in public insurance coverage, and a 2.8 percentage point decrease in private health insurance coverage, which are all statistically significant at the one percent level. These estimates correspond to a crowd-out rate of roughly 32 percent and imply the ACA Medicaid expansions had some effect

\footnotetext{
${ }^{5}$ I estimate a difference-in-differences model comparing expansion states to non-expansion states, controlling for indicators of single year of age, education, race, marital status, number of children, as well as the average annual state unemployment rate. States that expanded Medicaid after January 2014 are excluded from the sample, and I cluster standard errors at the state level.
} 
on crowding out of private health insurance coverage. ${ }^{6}$ My results are in line with prior estimates that show the ACA Medicaid expansions increased insurance coverage by 3 to 15.5 percentage points depending on the sample and empirical strategy (Simon, Soni, and Cawley 2016; Wherry and Miller, 2016; Kaestner et al., 2017; Courtemanche et al., 2017). Finally, the ACA Medicaid expansions increased healthcare utilization including preventative care and overnight hospital stays (Anderson et al., 2016; Shartzer, Long, and Anderson, 2016; Simon et al., 2016; Soni, Hendryx, and Simon, 2016; Wherry and Miller, 2016; Kaufman et al., 2017). Together, these results provide evidence the ACA Medicaid expansions led to an increase in demand for healthcare services that is likely to affect demand for nurses

\section{[INSERT TABLE 1 HERE]}

Given an increase in demand for healthcare services, employers can increase total nursing hours by hiring additional nurses or increasing hours of current nurses. The optimal choice to hire nurses or increase current nurse hours depends on the costs of the two options. To increase hours of current nurses, employers face the marginal cost of (overtime) wages plus the expected cost of medical errors due to nurse fatigue. The costs to hire additional nurses include the marginal cost of wages plus adjustment costs of hiring (fringe benefits, job search) and changing the level of employment. Small demand shocks are likely to result in an increase in hours while large increases in demand are necessary to overcome the costs of hiring to increase employment (Hamermesh, 1996, Chapter 6). Without knowing these details - the size of the demand shock, costs to employers, and the production technology, theory is unclear about how the 2014 ACA Medicaid expansions could affect nurse employment and hours.

\footnotetext{
${ }^{6}$ The crowd-out rate is calculated as the estimated effect on private health insurance coverage divided by the estimated effect on public health insurance coverage: $(0.028 / 0.088)=0.318$.
} 
An increase in demand for nurses should increase wages, but institutional factors may slow wage growth. Nurse wages may be sticky upwards to maintain the average quality of applicants (Heyes, 2005). Thus, despite an increase in demand, employers may be hesitant to increase wages in fear of attracting low quality nurses that could affect quality of care. Wage increases may also be delayed because of unions and contract stickiness. For example, wages of new hires and those currently employed may be tied to prior contracts which may be renegotiated at a date that occurs a period after the increase in demand.

\subsection{Changes in nurse staffing and quality of care}

Because the ACA Medicaid expansions may increase the demand for healthcare services and nurses, there may also be a change in nurse-patient ratios, hours worked, and the skill mix of nurses which can have consequences for patient outcomes (Aiken, Sochalski, and Lake, 1997; Tourangeau et al., 2006; Despins, Scott-Cawiezell, and Rouder, 2010). Decreases in nursepatient ratios are associated with worse patient outcomes (Aiken, et al.,2002; and Needleman, et $a l ., 2002)$ likely due to reductions in patient surveillance and increases in hours or overtime are associated with increased errors and adverse events (Rogers et al., 2004; Scott et al., 2006; Olds and Clarke, 2010; Bae and Fabry, 2014). Changes in the skill mix of nurses could also affect quality of care because lower skilled nurses may have less experience, training, and knowledge necessary to provide high quality care to patients. Average nurse skill-levels, measured by education or occupation, can decrease if low-skilled nurses are hired or work more hours in response to the increase in demand. Thus, the education and occupational composition of the nurse workforce may impact quality of care.

These theoretical outcomes assume no changes in how hospitals devote other resources to patient care or changes in the types of patients treated, i.e. patient health. In response to an 
increase in demand, hospitals may provide more resources in the form of equipment, training, or improved management practices to maintain quality of care. Healthcare providers may also provide more resources to patients with higher risk for worse outcomes. Quality of care measures can also be affected by patient health and the ACA Medicaid expansions could result in positive or negative patient health changes. Average patient health could decline if the ACA Medicaid expansions cause less healthy patients to seek care or increase negative health behaviors (ex ante moral hazard), while health could increase if the newly insured seek more preventative care. There is evidence of an increase in routine check-ups and self-assessed health, but little change in health behaviors among low-income childless adults after the ACA Medicaid expansions (Simon, Cawley, and Soni, 2017). In the general adult population, I do not find any changes in self-assessed health, but the ACA Medicaid expansions are associated with a small decrease in the probability of individuals reporting their health as "excellent" or "very good". 7 These results, of course, do not rule out the possibility that the ACA Medicaid expansions resulted in unobservable changes in health or patient-types. How the ACA Medicaid expansions affect quality of care is ambiguous because of the different potential responses to an increase in demand on both the supply and demand side of healthcare.

\subsection{Urban and rural differences and the ACA Medicaid expansions}

The previous discussion provides an overview of the potential effects of the ACA Medicaid expansions on nurse labor market outcomes and quality of care, but outcomes may be different in urban and rural areas due to differences in healthcare markets in these settings. Individuals in rural areas are more likely to be uninsured, older, and less healthy than those in urban areas (Meit et al., 2014). Evidence also suggests the 2014 ACA Medicaid expansions had

\footnotetext{
${ }^{7}$ A description of this exercise and the results are in Appendix A1.
} 
larger effects on healthcare demand in rural areas. Table 1 shows insurance coverage increased by 5 percentage points in urban areas (Panel B) and by nearly 10 percentage points in rural areas (Panel C). Similarly, Soni, Hendryx, and Simon (2017) find larger increases in insurance coverage in rural areas relative to urban areas among low-income childless adults. Additional evidence shows utilization, measured by Medicaid discharges, was higher in rural areas after the 2014 ACA Medicaid expansions (Kaufman et al., 2016). These results imply the increase in demand for healthcare services was larger in rural areas.

Relative to urban healthcare facilities, rural facilities tend to supply less-specialized care. Hospitals in rural areas tend to be smaller, with 47 percent having 25 or fewer beds while 41 percent of urban hospitals have 200 or more beds, and revenue from outpatient care, which does not require an overnight stay, has grown faster in rural hospitals (American Hospital Association, 2011). The rural healthcare workforce also tends to be less specialized and educated. The number of specialized physicians per capita is lower in rural areas (Meit et al., 2014) and rural nurses are generally lower skilled. Rural nurses are more likely to be LPNs, and rural RNs are less-educated than their urban counterparts. ${ }^{8}$ Thus, rural residents must often travel to urban hospitals to receive more specialized care (American Hospital Association, 2011; Meit et al., 2014).

Because of these differences, the ACA Medicaid expansions have different effects in urban and rural areas. A larger increase in insurance coverage and Medicaid discharges in rural areas is likely to result in a larger increase in demand for nurses in rural areas; however, the increase in demand in rural areas could be weaker due to a lack of available healthcare services, instead shifting demand for some healthcare services to urban areas where more specialized

\footnotetext{
${ }^{8}$ Prior to 2014, rural nurses were 10 percent more likely to be LPNs (statistically significant at the 1 percent level), and registered nurses in rural areas were 19 percent less likely to have at least a bachelor's degree (statistically significant at the 1 percent level). Author's calculations using the 2010-2013 American Community Surveys.
} 
services may be available. Thus, despite some evidence the ACA Medicaid expansions resulted in larger increases in insurance coverage and some measures of utilization in rural areas, it is not perfectly clear that there would also be a larger increase in demand for nurses in rural areas.

\subsection{Registered nurses and licensed practical nurses}

Registered and licensed practical nurses differ in the services they provide and their educational requirements. RNs generally perform a higher level of care and often work in specialized units or oversee other nurses. This specialization is reflected in each occupation's educational requirements. LPN educational requirements can be completed in one year, while RNs typically require at least a two-year degree and often a bachelor's. ${ }^{9}$ Because of the longer time to complete educational requirements, the supply of RNs is likely more inelastic than the supply of LPNs. Thus, RNs may be more responsive to an increase in demand along the intensive margin (hours) and LPNs may be more responsive along the extensive (employment) margin, particularly in the short period I study. Both LPNs and RNs can provide basic nursing care, but LPNs are more likely to be affected by an increase in demand for basic care because they can provide it at a lower cost. RNs, on the other hand, are more likely to be affected by an increase in demand for care that requires a higher level of specialization.

\section{Data and Sample Selection}

\subsection{Labor market data}

The nurse labor market data used in the study comes from two sources. To estimate the effects of the ACA Medicaid expansions on nurse employment, I use the annual surveys from 2010-2015 from the American Community Survey (ACS) (Ruggles et al., 2015). The ACS

\footnotetext{
${ }^{9}$ Bureau of Labor Statistics, U.S. Department of Labor, Occupational Outlook Handbook, 2016-17 Edition, Registered Nurses. https://www.bls.gov/ooh/healthcare/registered-nurses.htm. Accessed June 15, 2017.
} 
samples roughly three million individuals each year and collects information on an individual's demographic and geographic characteristics including employment status, occupation, education, race, state of residence, and the state where an individual is employed. To estimate state-by-year employment levels, I aggregate the data by the state where an individual works and survey year.

I use individual-level data from the monthly 2010-2016 Current Population Survey (CPS) (Flood et al., 2015) to estimate the effects of the ACA Medicaid expansions on hours worked and earnings. The CPS is a monthly survey of roughly 60,000 households and the main source of U.S. labor force data. Households are interviewed for four months, drop out of the survey for eight months, and then are interviewed for another four months. The CPS Outgoing Rotation Group (CPS-ORG) consists of a subset of individuals from the monthly CPS who are in their fourth or eighth month in the sample and currently employed as a wage or salaried worker. The CPS-ORG asks this subset of individuals about their type of pay (hourly or salary), hourly wage, usual hours worked per year, and usual hours worked per week. For non-hourly workers, I calculate their hourly wage as their reported usual weekly earnings divided by either: (1) usual hours worked per week or (2) hours worked last week if an individual reports that their usual hours vary. Following Hirsch and Schumacher (2012), I drop individuals from the CPS-ORG sample with extreme (hourly wages less than $\$ 3$ or $\$ 150$ and greater) or imputed earnings.

In both the ACS and CPS data, I restrict the sample to RNs and LPNs age 18-64 who are currently employed at the time of the survey and have at least a high school degree or equivalent. I also restrict my sample to nurses employed in healthcare provider industries to focus on those most likely to be impacted by the ACA Medicaid expansions. ${ }^{10}$

\footnotetext{
${ }^{10}$ These industries include offices of providers, outpatient care centers, hospitals, nursing care facilities, residential care facilities, and individual and family services. I also conduct a sensitivity check of my results by including
} 


\subsection{Quality of care data}

I use data from the U.S. Centers for Medicare and Medicaid Services (CMS) Hospital Compare data archive to estimate the effects of the ACA Medicaid expansions on quality of patient care. ${ }^{11}$ Hospital Compare was created in 2002 by the U.S. CMS and Hospital Quality Alliance to promote reporting of hospital quality measures and increase consumer access to information on hospital quality. For my purposes, the Hospital Compare archives contain hospital-level patient ratings of nursing care and hospital-acquired infection rates.

Patient ratings of nursing care come from the 2010-2015 Hospital Consumer Assessment of Healthcare Providers and Systems (HCAHPS) surveys. A random sample of patients completes the 32 question HCAHPS survey each year. I use four separate measures of quality that are the percent of patients who report (1) nurses always communicated well, (2) staff always responded when needed, (3) pain was always well controlled, and (4) staff always explained medication. Each outcome is a composite measure created from patient responses to at least two questions from the HCAHPS survey, and the composite measures are adjusted by the U.S. CMS to control for differences in hospital and patient mix. ${ }^{12}$ The composite measures capture patient experience that is associated with nurse staffing and skill mix, particularly through missed nursing care (Kalisch, 2006; Kalisch, Landstrom, and Hinshaw, 2009). I balance the samples to only include hospitals that are in the sample every year for a given measure.

The Hospital Compare archives also contain data on yearly hospital-acquired infection rates for catheter-associated urinary tract infections, central line-associated bloodstream

nurses in all industries in section 8.2. My results are similar in sign, magnitude, and statistical significance when including nurses in all industries.

${ }^{11}$ The archived data is available at https://data.medicare.gov/data/archives/hospital-compare. Accessed October 28, 2016.

${ }^{12}$ Section A2 of the Appendix lists the questions that comprise each composite measure. The composite measures are adjusted by patient age, education, self-rated health, type of admission, hospital ward. 
infections, colorectal surgical site infections, and abdominal surgical site infections. Catheterassociated urinary tract infections and central line-associated bloodstream infections have been identified as two standard patient-centered outcome measures of nursing quality of care by the National Quality Forum. ${ }^{13}$ I calculate hospital infection rates as the percentage of the number of infections per hospital day or by procedure depending on the type of infection. Central lineassociated bloodstream infection data is available from 2011-2015 while data for catheterassociated urinary tract infections, colorectal surgical site infections, and abdominal surgical site infections are available from 2012-2015. As with the patient ratings of nursing care, I use balanced samples for the infection rate analyses.

\subsection{Treatment and control states}

I restrict the main sample to control states that did not expand Medicaid and treatment states that expanded Medicaid coverage as of January 2014, omitting states that expand Medicaid coverage after 2014. The main sample includes 20 states that expanded Medicaid in 2014 and 24 states that have not expanded Medicaid. ${ }^{14}$ By limiting the sample to states that never expand Medicaid and states that expanded coverage in January 2014, I can analyze the pre-trends of the outcome variables and perform statistical tests to provide evidence of the validity of the differences-in-differences parallel trends assumption. I include all states in the sample for the nurse labor market regressions as a robustness check.

\footnotetext{
${ }^{13}$ National Quality Forum, "National Voluntary Consensus Standards for Nursing-Sensitive Care: An Initial Performance Measure Set". 2004. Report available at: http://www.qualityforum.org/WorkArea/linkit.aspx?LinkIdentifier=id\&ItemID=22094. Accessed June 16, 2016. ${ }_{14}$ The expansion states are: AR, AZ, CA, CO, CT, HI, IA, IL, KY, MD, MN, NV, NJ, NM, ND, OH, OR, RI, WA, WV. Control states include AL, DC, DE, FL, GA, ID, KS, MA, ME, MO, MS, NC, NE, NY, OK, SC, SD, TN, TX, UT, VA, VT, WI, WY. While DE, DC, MA, NY, and VT expanded Medicaid in 2014, I include them as control states, following Kaestner et al. (2017), because they previously expanded coverage to adults prior to 2014 that was equivalent to coverage in the ACA expansions. My results are similar in magnitude, sign, and statistical significance when including DE, DC, MA, NY, and VT as expansion states. These results are available in Table 13.
} 


\section{Empirical Strategy}

\subsection{Nurse labor market outcomes}

I use a difference-in-differences estimation strategy to measure the effect of the ACA Medicaid expansions on labor market outcomes for registered nurses. The employment regression is:

$$
y_{s t}=\beta_{1} \text { Expand }_{s t}+\boldsymbol{\alpha}_{s}+\lambda_{t}+\epsilon_{s t}
$$

In equation $1, y_{s t}$ is the $\log$ of employment in state $s$ in year $t$. Expand Ext $_{\text {in }}$ an indicator variable equal to one for expansion states after year 2013 and zero for non-expansion states in all years. State fixed effects, $\boldsymbol{\alpha}_{\boldsymbol{s}}$, control for unobservable differences between states and year fixed effects, $\lambda_{t}$, control for yearly differences common to all states. Standard errors are clustered at the state level.

For individual-level regressions of hours worked and earnings, I estimate the following equation:

$$
y_{i s q t}=\beta_{0}+\beta_{1} \text { Expand }_{s t}+\gamma^{\prime} \boldsymbol{X}_{\text {isqt }}+\boldsymbol{\alpha}_{\boldsymbol{s}}+\boldsymbol{\rho}_{\boldsymbol{q}}+\boldsymbol{\lambda}_{\boldsymbol{t}}+\epsilon_{i s q t}
$$

In equation $2, y_{\text {isqt }}$ is the number of hours worked last week or the hourly wage for individual $i$, in state $s$, in quarter $q$, in year $t .{ }^{15}$ As in equation 1, Expand $_{s t}$ is an indicator variable equal to one if state $s$ has expanded Medicaid coverage in year $t$ and zero if not. $\boldsymbol{X}_{\text {isqt }}$ is a vector of demographic indicator variables (single year of age, gender, race, citizenship status, education level, married, and number of children), an occupation indicator equal to one for RNs and zero for LPNs, and the yearly average state unemployment rate. State fixed effects, $\boldsymbol{\alpha}_{\boldsymbol{s}}$, control for average differences in hours and employment between states, quarter-of-year fixed effects, $\boldsymbol{\rho}_{\boldsymbol{q}}$,

\footnotetext{
${ }^{15}$ Results are robust to replacing the quarter and year fixed effects with monthly fixed effects, year fixed effects, or year and month fixed effects. These results are available by request.
} 
control for quarter-of-year differences common to all states, and year fixed effects, $\lambda_{t}$, control for yearly differences common to all states which may affect the nurse labor market. The standard errors are clustered at the state level.

In equations (1) and (2), $\beta_{1}$ represents the effect of ACA Medicaid expansions on the nurse labor market outcomes. The interpretation of $\beta_{1}$ as the causal effect of the ACA Medicaid expansions on nurse labor market outcomes requires two assumptions. First, the decision to expand Medicaid should be exogenous to unobservable factors that may affect states' decision to expand Medicaid and nurse labor market outcomes. This assumption would be violated if states did not expand Medicaid in anticipation of changes related to the demand for healthcare services that would subsequently affect demand for nurses. The decision to expand Medicaid was largely related to state political leanings and state Medicaid budget concerns (Jacobs and Callaghan, 2013) that I control for by including state fixed effects to capture the influence of time invariant factors as well as state unemployment rates that control for economic conditions presumably related to state budgets.

Second, the interpretation of $\beta_{1}$ as a causal effect requires that outcomes in treated and control states follow parallel trends prior to the expansion of Medicaid in treated states. I assess the validity of this assumption in multiple ways. First, I visually check for parallel trends by plotting the means of outcomes for treated and controls states before and after the change in policy. Second, I formally test for differences in pre-trends between expansion and control states using the ACS and CPS data from 2010-2013. I include a linear time trend variable in equations (1) and (2) and replace the treatment indicator, Expand $_{s t}$, with a variable that is an interaction between an indicator for being an expansion state and the linear time trend. All outcomes, control variables, and fixed effects are the same as in the difference-in-differences models in 
equations (1) and (2), respectively. If nurse labor market outcomes were trending differently in expansion states, then this would bias the difference-in-differences estimates. The interaction variable in the ideal case should be small and not statistically significant to provide evidence expansion and control states follow similar pre-trends. Finally, in the difference-in-differences models, I relax the parallel trends assumption by including state-specific linear time trends to control for potential trends in unobservable individual characteristics.

To provide additional evidence of the validity of the difference-in-differences identifying assumptions, I also estimate placebo regressions. These regressions use samples of two broad occupational groups that should not be affected by the ACA Medicaid expansions to examine impacts on their employment, hours and wages: (1) teachers and (2) architects and engineers. Because these occupations are unrelated to providing healthcare services, there should not be any statistically significant effects. I also check the sensitivity of the results on nurse labor market outcomes to changes in weighting and sample selection.

\subsection{Quality of care}

To estimate the effect of the ACA Medicaid expansions on hospital-level quality of care outcomes, I use the following equation:

$$
y_{i s t}=\boldsymbol{\alpha}_{\boldsymbol{i}}+\beta \text { Expand }_{s t}+\boldsymbol{\rho}^{\prime} \boldsymbol{X}_{\boldsymbol{s t}}+\boldsymbol{\lambda}_{\boldsymbol{t}}+\epsilon_{i t}
$$

In equation (3), $y_{i s t}$ is a composite patient rating of care measure or an infection rate for hospital $i$ in state $s$ in year $t$. Expand $d_{s t}$ is an indicator variable equal to one if state $s$ has expanded Medicaid coverage in year $t$ and zero if not. I include hospital fixed effects, $\boldsymbol{\alpha}_{\boldsymbol{i}}$, to control for average differences across hospitals and year fixed effects, $\lambda_{t}$, to control for yearly differences common to all hospitals. $\boldsymbol{X}_{\boldsymbol{s t}}$ is a vector of state controls including population shares (black, 
Asian, other race, female, immigrant, rural), average age, and the yearly average state unemployment rate. Because the Hospital Compare data has limited information on hospital characteristics, I am unable to control for time-varying hospital characteristics such as nurse staffing, case loads, or hospital resources devoted to patient care. Thus, results from these estimates should be interpreted as an association between the ACA Medicaid expansions and quality of care rather than a causal effect of the expansions on quality. Standard errors are clustered at the state level.

\section{Results}

\subsection{Parallel trends in outcomes prior to 2014 ACA Medicaid expansions}

Figures 1-3 plot the unadjusted means and trends of the nurse labor outcomes for treatment and control states. Figure 1 plots the mean of employment (in logs) in treatment and control states. Employment is higher in treatment states, but the pre-2014 trends in employment appear similar in expansion and control states. Both expansion and control states seem to experience a similar change in employment on average after 2014. In Figure 2, mean hours are higher in control states and the pre-2014 trend appears to be slightly lower in treatment states. After 2014, there is a visible jump in the trend for hours worked in expansion states but no similar change for control states. Figure 3 plots the mean hourly wage (in logs). Treatment and control states follow similar trends prior to 2014 , and there is little change in either group after 2014.

In Figures 1 through 3, there are no visible trend differences prior to the Medicaid expansions. Table 2 provides results of tests for equivalent pre-trends for each of the nurse labor market outcomes. The variable of interest, $\left(\right.$ Trend $\left._{t}\right) \times\left(\right.$ Expansion $\left._{s}\right)$, is not statistically 
significant at conventional levels for the employment and hours outcomes, but wages in expansion states were trending below control states prior to 2014. These estimates provide supporting evidence expansion and control states followed similar trends in nurse employment and hours prior to the 2014 ACA Medicaid expansions and supports the validity of the difference-in-differences research design; however, the declining trend in wages in expansion states may make it difficult to detect an increase in wages following the expansions.

\section{[INSERT TABLE 2 HERE]}

\subsection{Difference-in-differences estimates}

\subsubsection{Nurse labor market outcomes}

Table 3 shows the results from the employment regressions under two specifications. For the estimate in column one, I regress the log of employment on the treatment indicator, state fixed effects, and year fixed effects. Column two adds state-specific linear time trends to control for differential time trends between states. In both cases the estimates are positive, although the estimate decreases when I add time trends, but the estimates are not statistically significant. Nevertheless, the 95 percent confidence intervals constructed from these estimates rule out large negative employment effects.

\section{[INSERT TABLE 3 HERE]}

The results from the hours and hourly wage regressions are shown in Table 4. Column one contains estimates from simple difference-in-difference in regressions that regress the outcome on the treatment indicator $\left(\right.$ Expand $\left._{s t}\right)$, state fixed effects, quarter-of-year fixed effects, and year fixed effects. I add additional controls to the regression in each successive column. Column two adds demographic controls, column three adds the state unemployment rate, and 
column four adds state-specific linear time trends to the full set of controls. In panel A, the ACA Medicaid expansions increase hours worked by 0.46 hours per week without any demographic or state controls, an effect that is statistically significant at the ten percent level. Moving to column three in panel $\mathrm{A}$, the effect increases to 0.55 and is statistically significant at the five percent level. Relative to the pre-2014 mean, this estimate implies the Medicaid expansions increase hours worked per week by 1.5 percent. The estimate also increases and remains statistically significant when I add state-specific linear time trends in column 4. The estimates of the ACA Medicaid expansions on the hourly wage in panel B are not statistically significant in any of the specifications and become positive when I include state-specific linear time trends. These results show the ACA Medicaid expansions increased nurse hours worked by 1.5 percent ( 0.55 hours) in my preferred specification (Table 4, panel A, column three), but did not have statistically significant effects on wages.

\section{[INSERT TABLE 4 HERE]}

To further understand the increase in nurses' hours, I estimate how the ACA Medicaid expansions affect the distribution of hours worked per week by re-estimating equation (2) at five points in the distribution of hours worked. Thus, $y_{i s q t}$, is an indicator for working less than 25 hours, working less than 35 hours or less, working at least 35 hours, working at least 40 hours, or working at least 50 hours in the last week.

\section{[INSERT TABLE 5 HERE]}

The results from these regressions are shown in Table 5 and summarized in Figure 4 that plots the coefficient and 95 percent confidence intervals for the treatment variable, Expand $d_{s t}$, from these regressions. According to these results, the ACA Medicaid expansions resulted in a 
shift from part-time to full-time work. The probability of working at least 35 hours a week increased by four percentage points (statistically significant at the one percent level), and the probability of working at least 40 hours a week increased by 2.8 percentage points (statistically significant at the five percent level). This shift in the distribution of hours worked implies that employers increased hours for workers in the lower end of the distribution after an increase in demand for care from the ACA Medicaid expansions. The cost associated with increasing hours for part-time workers is likely lower for two reasons. First, given an increase in hours, the marginal cost of increasing hours is higher for full-time workers because full-time workers are more likely to receive higher wages and may receive overtime pay. Second, the expected cost of adverse outcomes is higher for full-time workers who may suffer from fatigue if their hours increase.

\subsubsection{Quality of care outcomes}

The estimated effects on patient ratings of nursing care, reported in Table 6 , are positive for nurse communication, staff response, and explaining medication, negative for controlling pain, but all the estimated effects are imprecise. In addition, the estimated coefficients are small. For "staff always responded when needed", patient ratings could have decreased by at most 0.7 percent relative to the pre-2014 mean. ${ }^{16}$ It is difficult to conclude the 2014 ACA Medicaid expansions are associated with any large negative changes in patient experiences with nursing care because the coefficient estimates are mostly positive, and negative effects constructed under 95 percent confidence intervals are small relative to their means.

[INSERT TABLE 6 HERE]

\footnotetext{
${ }^{16}$ Calculated using 95 percent confidence interval.
} 
Table 7 shows the estimates for the four hospital-acquired infection rates. The ACA Medicaid expansions are associated with an 0.019 percentage point increase in central line associated bloodstream infections which is statistically significant at the five percent level and represents an effect that is over 21 percent of the mean. Estimates for the other three hospitalacquired infection rates are not statistically significant at conventional levels. Of these outcomes, estimates on the effects on catheter associated urinary tract infections and abdominal surgical site infections are positive while the estimated effect on colo-rectal surgical site infections is negative. I cannot rule out that the ACA Medicaid expansions are associated with large changes in infection rates from the 95 percent confidence intervals. The largest effect is for abdominal surgical site infections that could have increased by 31 percent or decreased by 20 percent relative to the pre-2014 mean.

\section{[INSERT TABLE 7 HERE]}

While I find a statistically significant increase in central-line associated bloodstream infections, none of the estimated effects on the other quality of care measures are statistically significant. The statistically insignificant results may be also inconsistent with a change in quality of care even if the coefficients are simply taken at face value. For example, the increase in some infection rates suggests the ACA Medicaid expansions are associated with decreases in quality, while the increase in some patient ratings suggests an increase in quality. The signs of the effects are also inconsistent in both the patient ratings and infection rate outcomes. Thus, it is difficult to infer that the ACA Medicaid expansions decreased quality of care given the imprecise estimates and inconsistent results. Furthermore, since decreases in quality of care are associated with fatigue from overtime hours and the ACA Medicaid expansions increased hours to more full-time work, it is unlikely fatigue could result in a change in quality of care. 


\section{Heterogeneous effects: location and occupation}

\subsection{Urban and rural}

To examine differences in urban and rural outcomes, I separate the sample into two groups, nurses in metropolitan areas ("urban") and non-metropolitan areas ("rural"), and reestimate the models for labor market outcomes in equations 1 and 2. Table 8 shows the labor market results for these separate analyses. Similar to my main results, I do not find any statistically significant effects on employment in urban or rural areas. The ACA Medicaid expansions are associated with a statistically significant increase in hours for both urban and rural nurses, but the increase in hours for rural nurses is over four times the size of the response among urban nurses. Relative to their pre-2014 means, hours increased by 4.4 percent among rural nurses (1.64 hours) and 1 percent among urban nurses (0.39 hours). I do not find any statistically significant effects on the hourly wage rate of urban or rural nurses. The difference in the magnitudes of the effects on hours worked in rural and urban areas is consistent with the evidence from prior research that shows the 2014 ACA Medicaid expansions caused larger insurance take-up and utilization in rural areas.

\section{[INSERT TABLE 8 HERE]}

A caveat to the results for hours worked is that the CPS data reports the urban/rural status of where individuals live, but not the urban/rural status where individuals work. Thus, some of the change observed for hours among rural nurses could potentially be driven by nurses who live in rural areas yet work in urban areas. For this to be an important source of bias, rural nurses who work in urban areas would have to be a relatively large proportion of rural nurses and work more hours than nurses who live and work in urban areas after the ACA Medicaid expansions. In the 2010-2015 ACS data, roughly 38 percent of rural-residing nurses commute to urban areas, and I 
do not find any statistically significant change in nurse commuting patterns from rural to urban areas in response to the Medicaid expansions that could partially explain the larger increase in hours among rural nurses. ${ }^{17}$ Thus, the larger increase in hours worked for rural-residing nurses does not appear to be driven by changes in hours worked by the portion who work in urban areas.

I also examine heterogenous effects of the ACA Medicaid expansions on quality of care by separating the sample of hospitals into urban and rural hospitals and re-estimate the quality of care models of equation 3. The results for the nursing care measures are shown in Table 9, and the results for hospital-acquired infections in Table 10. There is a statistically significant increase in central-line associated bloodstream infections associated with the ACA Medicaid expansions among rural hospitals, but generally, the effects for both urban and rural hospitals are similar to the main results. Point estimates vary in direction with respect to changes in quality, patient rating effects are small, and hospital-acquired infection rates have large confidence intervals. Thus, the evidence regarding effects of the ACA Medicaid expansions on quality in urban or rural hospitals is inconclusive.

[INSERT TABLE 9 HERE]

[INSERT TABLE 10 HERE]

\subsection{Licensed practical nurses and registered nurses}

Thus far, my results show nurses' hours worked increased after the 2014 ACA Medicaid expansions, but outcomes may be different for LPNs and RNs due to differences in supply and demand specific to these occupations. To examine differences in labor market outcomes between

\footnotetext{
${ }^{17}$ I formally test for changes in rural-to-urban commuting using the 2010-2015 ACS data. A description of this exercise and the results are in Appendix A3.
} 
occupations, I re-estimate my main difference-in-difference labor market models separately for LPNs and RNs.

Table 11 shows the results for the labor market outcomes for LPNs in panel A and RNs in panel B. LPN employment increased by 15 percent and hours worked increased by 0.89 hours (2.4 percent relative to the pre-2014 mean) after the ACA Medicaid expansions. Both effects are statistically significant at the five percent level. I do not find any statistically significant effects on employment of RNs, but their hours worked increased by 0.46 hours ( 1.2 percent relative to the pre-2014 mean), and effect that is statistically significant at the 10 percent level. I do not find any statistically significant effects on wages. The increase in LPN employment suggests the increase in demand was large enough to overcome adjustment costs of hiring. Furthermore, the larger effects for LPNs could indicate the ACA Medicaid expansions increased demand for relatively basic nursing care that can be provided by LPNs at lower costs to providers.

\section{[INSERT TABLE 11 HERE]}

\section{Placebo and sensitivity checks}

\subsection{Placebo regressions: teachers and engineers}

While I find evidence of an increase in demand, my results may be driven by other unobservable factors that are associated with the ACA Medicaid expansions and affect the labor market for nurses. According to my theoretical framework, the ACA Medicaid expansions

increase demand for healthcare services, thereby increasing demand for healthcare related occupations. Therefore, the expansions should not affect labor market outcomes of occupations unrelated to healthcare. If there are unobservable factors associated with the ACA Medicaid expansions that increase demand for workers generally, then I should also find an association 
between the expansions and labor market outcomes of unrelated occupations. To test this, I reestimate the difference-in-differences models for the labor market outcomes for two samples of occupations that should not be affected by the ACA Medicaid expansions: (1) teaching occupations and (2) architectural and engineering occupations.

Table 12 shows the results from the placebo regressions. For both occupation groups, I do not find any statistically significant effects on employment, hours, or the hourly wage. The results from these placebo regressions provide evidence the ACA Medicaid expansions are not correlated with unobservable factors that would result in a general increase in demand for occupations.

[INSERT TABLE 12 HERE]

\subsection{Changes in weighting and sample for nurse labor market outcomes}

I check the sensitivity of my nurse labor market results to the removal of sample weights and changes to the sample. The estimates from these alternative specifications are shown in Table 12. Column one reports the estimates from the main specifications in equations (1) and (2). Column two re-estimates equation (2) without the CPS sample weights as suggested by Solon, Haider, and Wooldridge (2015) for the estimation of causal treatment effects. Column three includes nurses in all industries in the samples. In column 4, I recode the treatment variable to include Washington D.C., Delaware, Massachusetts, New York, and Vermont as ACA Medicaid expansion states. These states were included in the control group in my main sample because each state had previous public health insurance expansions prior to 2014 that were equivalent to the Medicaid expansion, but also adopted the Medicaid expansions in 2014. In column 5, I remove observations from the first six months of 2014 because there may be a delay between the implementation of the expansions, insurance take-up, and the increase in demand for healthcare 
services. Finally, column 6 includes all states, and I recode the treatment variable to equal one for the seven states that expanded Medicaid after January 2014 according to their respective implementation dates. ${ }^{18}$

Overall, the results from these sensitivity checks are similar in sign, magnitude, and statistical significance to the main specification estimates for each outcome. For the employment outcome, the major difference is the increase in employment is statistically significant at the 10 percent level when I include nurses in all industries, but both estimates are similar in magnitude. All the estimates show an increase in hours that is statistically significant at the five percent level and similar in magnitude to the main estimates. Consistent with a delay between implementation of the expansions and the increase in healthcare and demand for nurse, the estimated increase in hours is larger than the main estimate when I drop the first six months of 2014 and smaller when I include states that expanded Medicaid after January 2014.

\section{[INSERT TABLE 13 HERE]}

\section{Discussion}

In January 2014, 25 states expanded Medicaid coverage to adults with incomes less than 138 percent of the federal poverty line as part of the 2010 Patient Protection and Affordable Care Act. These expansions were designed to increase health insurance coverage and access to healthcare for low-income adults. Research shows the ACA Medicaid expansions increased health insurance coverage and utilization of healthcare services, particularly among the targeted population of low-income adults, but there is little work on how the expansions affected healthcare providers. This paper provides some of the first evidence on how the insurance

\footnotetext{
${ }^{18}$ The states are Michigan (4/1/2014), New Hampshire (8/15/2014), Pennsylvania (1/1/2015), Indiana (2/1/2015), Alaska (9/1/2015), Montana (1/1/2016), and Louisiana (7/1/2016).
} 
demand shock from the ACA Medicaid expansions affected nurse labor market outcomes and quality of nursing care.

I use the 2014 ACA Medicaid expansions as a plausibly exogenous increase in demand for nurses to identify effects on nurse labor market outcomes, patient ratings of nursing care, and hospital-acquired infection rates. I find the 2014 ACA Medicaid expansions increased hours worked per week by nurses by 1.6 percent overall, but there are heterogeneous effects in labor market outcomes between geographic areas and nurse occupations. Prior research shows increases in insurance coverage and utilization from the ACA Medicaid expansions were larger in rural areas, and this is consistent with my results that show a larger impact in rural nurse labor markets where hours worked per week increased by 4.4 percent ( 1.56 hours) for rural nurses and 1 percent (0.39 hours) for urban nurses. Separating the samples by occupation, I find employment of LPNs increased by 15 percent, and hours worked per week increased for LPNs and RNs by 2.5 percent ( 0.89 hours) and 1.2 percent ( 0.46 hours $)$, respectively.

The heterogeneous effects highlight two possible effects of the ACA Medicaid expansions. First, consistent with other research, the ACA Medicaid expansions had larger effects in rural areas. Thus, the ACA Medicaid expansions likely improved rural access to care and could be effective in improving rural health. Second, I find larger effects on LPNs, who provide basic nursing services, and nurses in rural areas, where healthcare services tend to be less specialized. This provides evidence that the ACA Medicaid expansions increased demand for relatively basic and preventative healthcare rather than specialized care, and it is consistent with prior research that shows the ACA Medicaid expansions increased utilization of preventative care. 
I also examine the association between the 2014 ACA Medicaid expansions and quality of care, which has been previously linked to changes in nurse staffing. I find the expansions are associated with a 0.018 percentage point increase in the central line-associated bloodstream infection rate, but the estimated effects of the ACA Medicaid expansions on other quality of care measures are imprecise. Additionally, the direction of the effects across all quality measures do not consistently show a decrease in quality. Given the lack of consistency in these results, I cannot conclude that the ACA Medicaid expansions affected quality of care. Despite the insignificant results, nurse fatigue is unlikely to have caused changes in quality of care. The increase in nurse hours was driven by a shift from part-time to full-time work whereas fatigue and adverse events have generally been associated with overtime hours. Future research can further explore changes in quality of care after the ACA Medicaid expansions by looking at changes in staffing, capital inputs, and technology in the healthcare sector. 


\section{References}

Aiken, L. H., Clarke, S. P., Sloane, D. M., Sochalski, J., and Sibler, J. H. 2002. Hospital Nurse Staffing and Patient Mortality, Nurse Burnout, and Job Dissatisfaction. Journal of the American Medical Association, 288(16): 1987-1993.

Aiken L. H., Sochalski, J, and Lake E. T. 1997. Studying Outcomes of Organizational Change in Health Services. Medical Care, 35(11): NS6-NS18.

American Hospital Association. 2011. The Opportunities and Challenges for Rural Hospitals in an Era of Health Reform. http://www.aha.org/research/reports/tw/11apr-tw-rural.pdf

Anderson, A. 2014. The Impact of the Affordable Care Act on the Health Care Workforce. The Heritage Foundation.

Anderson, M. E., Glasheen, J. J., Anoff, D., Pierce, R., Lane, M., and Jones, C. D. 2016. Impact of State Medicaid Expansion Status on Length of Stay and In-Hospital Mortality for General Medicine Patients at US Academic Medical Centers. Journal of Hospital Medicine, 11(12): 847-852.

Bae, S. and Fabry, R. 2014 Assessing the Relationships between Nurse Work Hours/Overtime and Nurse and Patient Outcomes: Systematic Literature Review. Nursing Outlook, Vol. 62: 138-156.

Buerhaus, P.I., Auerbach, D.I., and Staiger, D. O. 2009. The Recent Surge in Nurse Employment: Causes and Implications. Health Affairs, 28(4): w657-w668.

Cook, A., Gaynor, M., Stephens, M. Jr., Taylor, L. 2012. The Effect of a Hospital Nurse Staffing Mandate on Patient Health Outcomes: Evidence from California's Minimum Staffing Regulation. Journal of Health Economics, 31(2): 340-348.

Courtemanche, C., Marton, J., Ukert, B., Yelowitz, A., and Zapata, D. 2017. Early Impacts of the Affordable Care Act on Health Insurance Coverage in Medicaid Expansion and NonExpansion States. Journal of Policy Analysis and Management, 36(1): 178-210.

Despins, L. A., Scott-Cawiezell, J, and Rouder, J.N. 2010. Detection of Patient Risk by Nurses: a Theoretical Framework. Journal of Advanced Nursing, 66(2): 465-74.

Cunningham, R. 2013. On Workforce Policy, Consensus is Hard to Find. Health Affairs, 32(11): 1881-1886.

Evans, W. N., and Kim, B. 2006. Patient Outcomes When Hospitals Experience a Surge in Admissions. Journal of Health Economics, 25(2): 365-388. 
Flood, S., King, M., Ruggles, S., Warren, J.R. Integrated Public Use Microdata Series, Current Population Survey: Version 4.0. [dataset]. Minneapolis: University of Minnesota, 2015.

Ghosh, A., B. Sommers and K. Simon. 2017. The Effect of State Medicaid Expansions on Prescription Drug Use. National Bureau of Economic Research, Working Paper No. 23044.

Gooptu, A., Moriya, A., Simon, K., and Sommers, B. 2016. Medicaid Expansion Did Not Result In Significant Employment Changes or Job Reductions in 2014. Health Affairs, 35(1): 111-118.

Gruber, J., and Kleiner, S. A. 2012. Do Strikes Kill? Evidence from New York State. American Economic Journal: Economic Policy, 4(1): 127-157.

Hamermesh, D. 1996. Labor Demand. Princeton University Press

Heyes, A. 2005. The Economics of Vocation or 'Why is a Badly Paid Nurse a Good Nurse'? Journal of Health Economics, 24(3): 561-569.

Hirsch, B. T. and Schumacher, E. J. 2012. Underpaid or Overpaid? Wage Analysis for Nurses Using Job and Worker Attributes. Southern Economic Journal, 78(4): 1096-1119.

Hu, L., Kaestner, R., Mazuder, B., Miller, S., and Wong, A. 2016. The Effect of the Patient Protection and Affordable Care Act Medicaid Expansions on Financial Well-Being. National Bureau of Economic Research, Working Paper No. 22170.

Jacobs, L.R., \& Callaghan, T. 2013. Why States Expand Medicaid: Party, Resources, and History. Journal of Health Politics, Policy and Law, 38(5): 1023-1050

Kaestner, R., Garret, B., Chen, J., Gangopadhyaya, A., and Fleming, C. 2017. Effects of ACA Medicaid Expansions on Health Insurance Coverage and Labor Supply. Journal of Policy Analysis and Management, 36(3): 608-642.

Kalisch, B. J. 2006. Missed Nursing Care: A Qualitative Study. Journal of Nursing Care Quality, 21(4): 306-313.

Kalisch, B. J., Landstrom, G. L., and Hinshaw, A. S. 2009. Missed Nursing Care: A Concept Analysis. Journal of Advanced Nursing, 65(7): 1509-1517.

Kaufman, B. G., Reiter, K. L., Pink, G. H., and Holmes, G.M. 2016. Medicaid Expansions Affect Rural and Urban Hospitals Differently. Health Affairs, 35(9): 1665-1672.

Klevens, R. M., Edwards, J.R., Richards, C. L. Jr., Horan, T.C., Gaynes, R. P., Pollock, D. A., Cardo, D. M. 2007. Estimating Health Care-Associated Infections and Deaths in U.S. Hospitals, 2002. Public Health Reports, 122(2): 160-166.

Leung, P. and Mas, A. 2016. Employment Effects of the ACA Medicaid Expansions. National Bureau of Economic Research, Working Paper No. 22540. 
Meit, M., Knudson, A., Tzy-Chyi Yu, A., Tanenbaum, E., Ormson, E., TenBroeck, S., Bayne, A., and Popat, S. 2014. The 2014 Update of the Rural-Urban Chartbook. The Rural Health Reform Policy Research Center.

Needleman, J., Buerhaus, P. I., Mattke, S., Stewart, M., and Zelvinsky, K. 2001. Nurse Staffing Levels and the Quality of Care in Hospitals. The New England Journal of Medicine, 346(22): 1715-1722.

Needleman, J., Buerhaus, P., Pankratz, V. S., Leibson, C. L., Stevens, S. R., Harris, M. 2011. Nurse Staffing and Inpatient Hospital Mortality. The New England Journal of Medicine, 364(11): 1037-145.

Olds D. M. and Clarke S. P. 2010. The Effect of Work Hours on Adverse Events and Errors in Health Care. Journal of Safety Research, 41(2):153-162.

Rogers, A. E., Hwang, W., Scott, L. D., Aiken, L. H., and Dinges, D. F. 2004. The Effect of Working Hours on Hospital Staff Nurses and Patient Safety. Health Affairs, 23(4): 202212.

Ruggles, S., Genadek, K., Goeken, R., Grover, J., and Sobek, M. Integrated Public Use Microdata Series: Version 6.0 [dataset]. Minneapolis: University of Minnesota, 2015.

Scott, L. D., Rogers, A. E., Hwang, W., and Zhang, Y. 2006. Effects of Critical Care Nurses' Work Hours on Vigilance and Patients' Safety. American Journal of Critical Care, 15(1): 30-37.

Shartzer, A., Long, S. K., Anderson, N. 2016. Access to Care and Affordability Have Improved Following Affordable Care Act Implementation; Problems Remain. Health Affairs, 35(1): 1-8.

Simon, K. Soni, A., and Cawley, J. 2017. The Impact of Health Insurance on Preventive Care and Health Behaviors: Evidence from the First Two Years of the ACA Medicaid Expansions. Journal of Policy Analysis and Management, 36(2): 267-491.

Solon, G., Haider, S.J., and Wooldridge, J.M. 2015. What Are We Weighting For? Journal of Human Resources, 50(2): 301-316.

Soni, A., Hendryx, M., and Simon, K. 2017. Medicaid Expansion Under the Affordable Care Act and Insurance Coverage in Rural and Urban Areas. Journal of Rural Health, 33(2): 217226.

Stone, P. W., Mooney-Kane, C., Larson, E. L., Horan, T., Glance, L. G., Zwanziger, J., and Dick, A. W. 2007. Nurse Working Conditions and Patient Safety Outcomes. Medical Care, 45(6): 571-578.

Sullivan, D. 1989. Monopsony Power in the Market for Nurses. Journal of Law and Economics, 28(2): 211-236. 
Tourangeau, A. E., Doran, D. M., McGillis Hall, L. M., O’Brien Pallas, L., Pringle, D., Tu, J. V., and Cranley, L. A. 2006. Impact of hospital nursing care on 30-day mortality for acute medical patients. Journal of Advanced Nursing; 57(1):32-44.

U.S. Department of Health and Human Services. 2014. The Future of the Nursing Workforce: National and State-level Projections, 2012-2025. https://bhw.hrsa.gov/sites/default/files/bhw/nchwa/projections/nursingprojections.pdf.

Wherry, L.R. and Miller, S. 2016. Early Coverage, Access, Utilization, and Health Effects Associated with the Affordable Care Act Medicaid Expansions: A Quasi-experimental Study. Annals of Internal Medicine, 164(12): 795-803.

Zimlichman, E., Henderson, D., Tamir, O., Franz, C., Song, P., Yamin, C. K., Keohane, C., Denham, C. R., and Bates, D. W. 2013. Health Care-Associated Infections: A Metaanalysis of Costs and Financial Impact on the U.S. Health Care System. Journal of the American Medical Association: Internal Medicine, 173(22): 2039-2046. 


\section{Figures}

Figure 1 - Trends in mean $\log ($ employment $)$ of nurses in treatment and control states

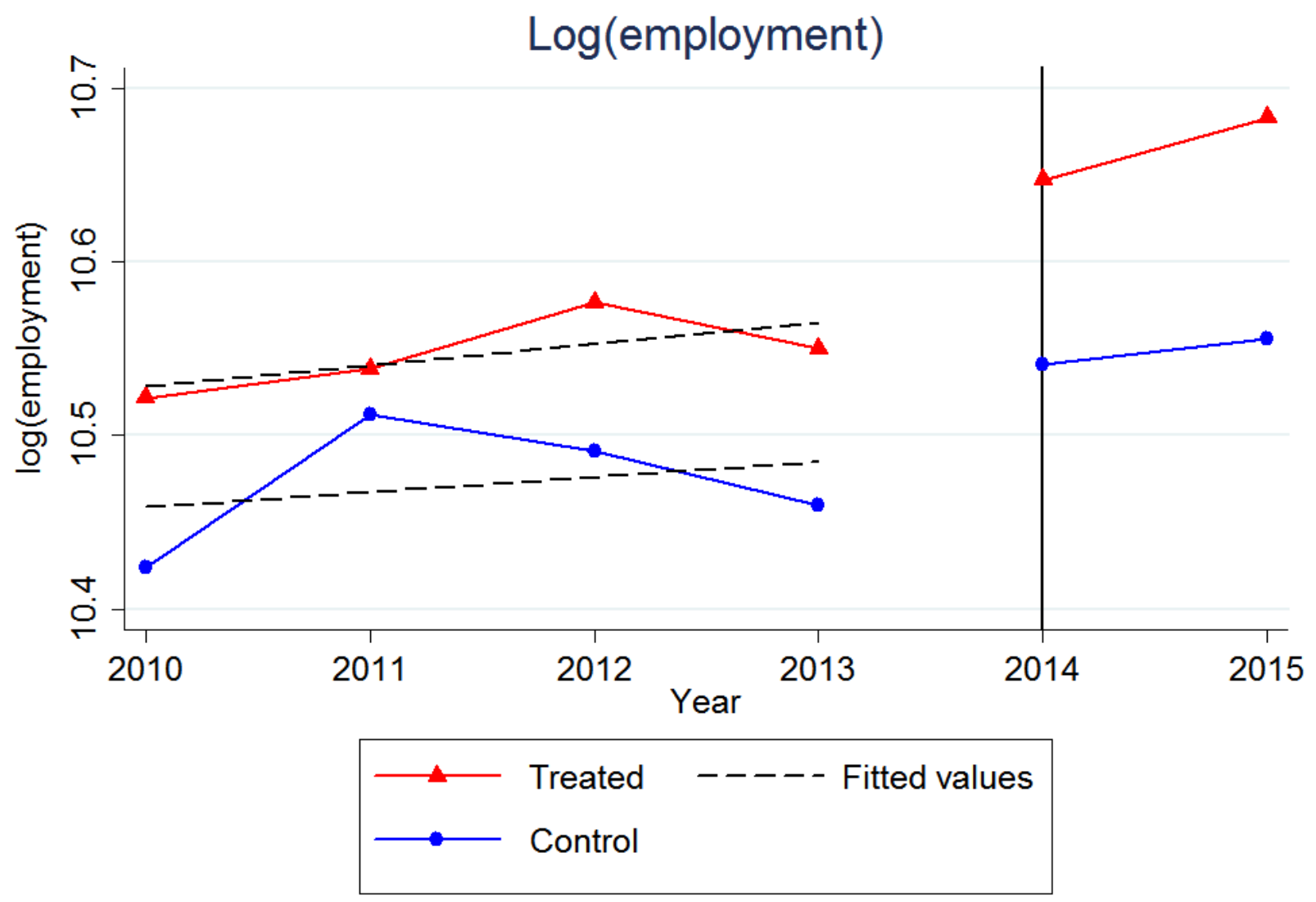


Figure 2 - Trends in mean nurses' hours worked per week in treatment and control states

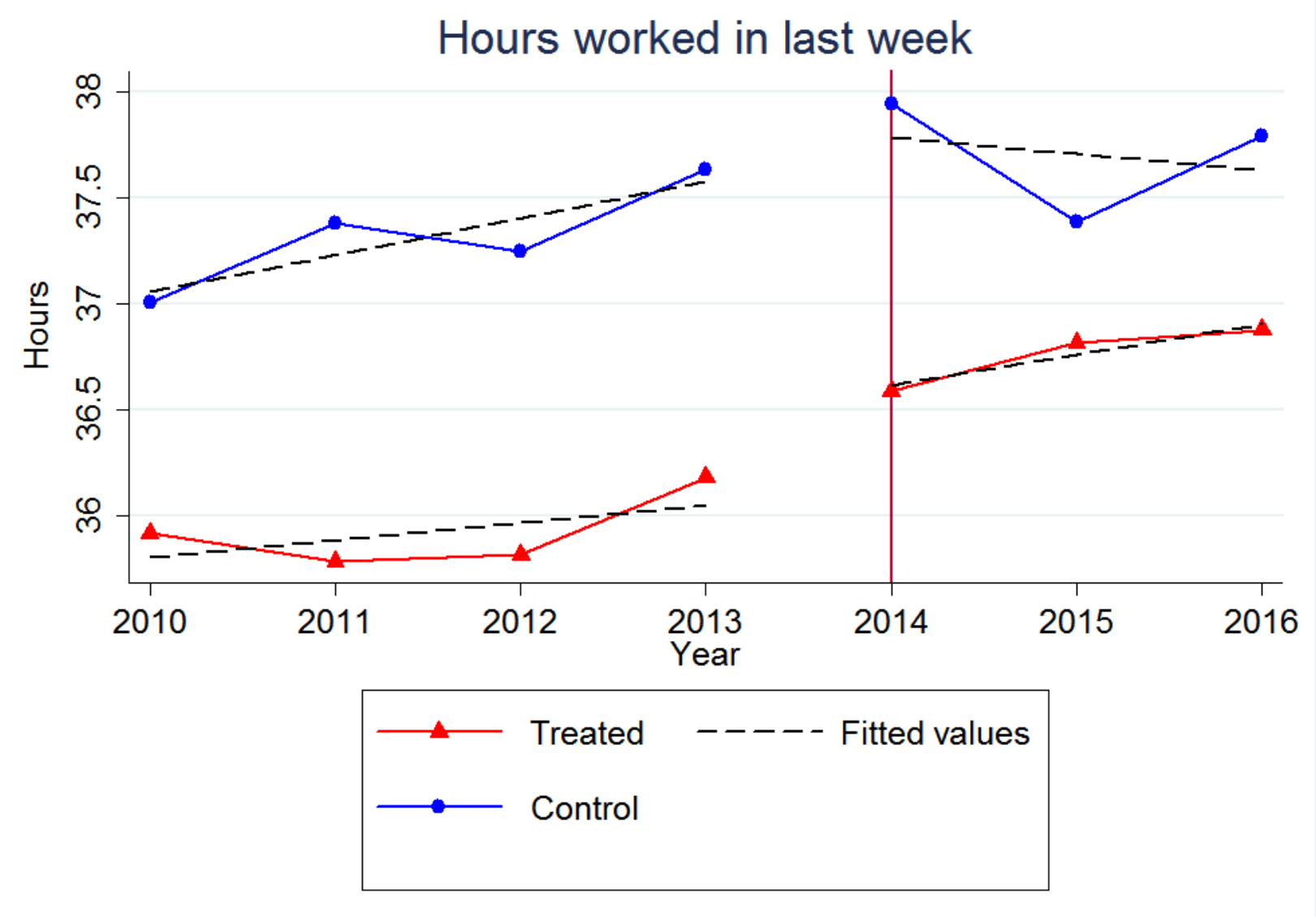


Figure 3 - Trends in mean $\log ($ hourly wage) of nurses in treatment and control states

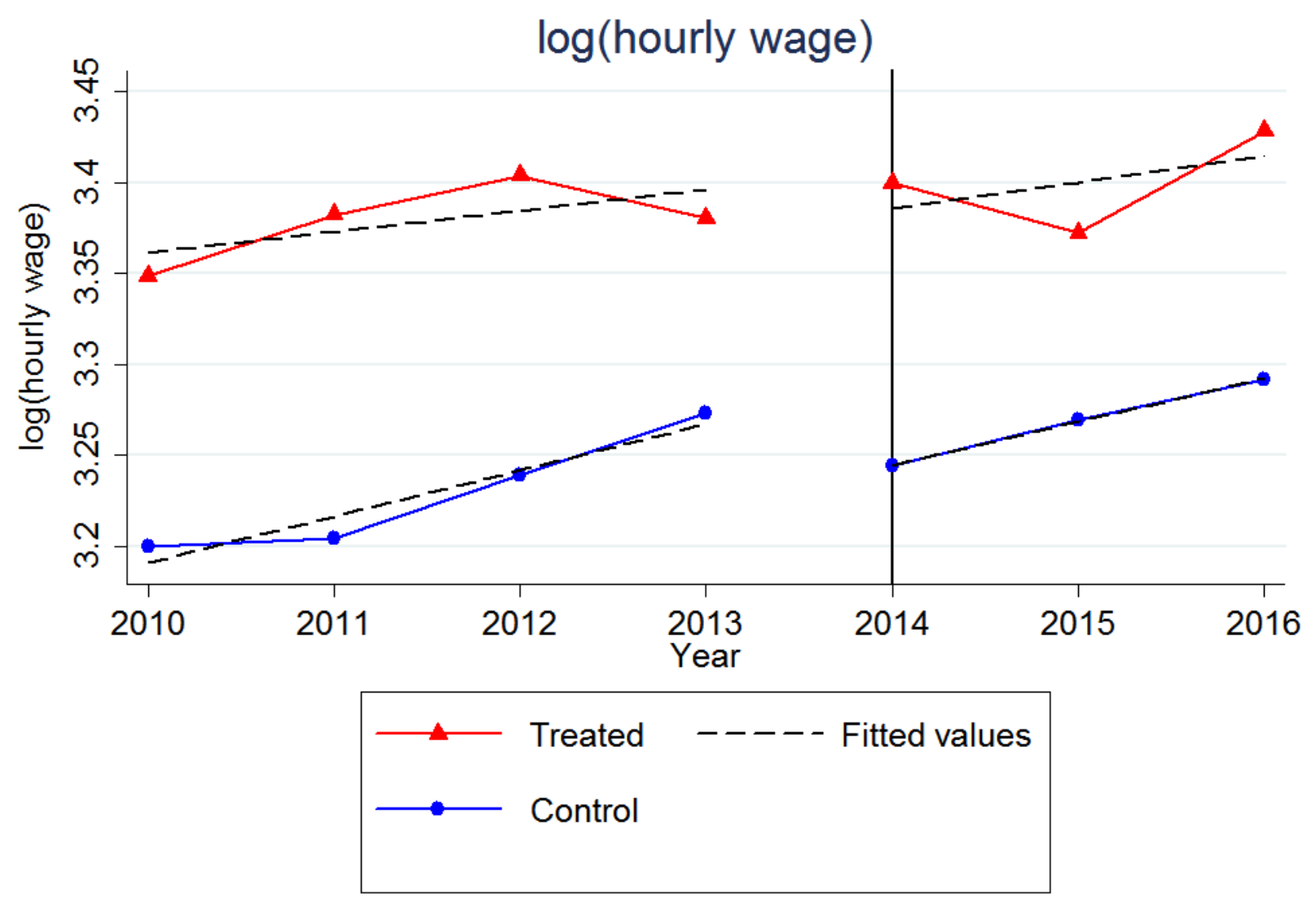


Figure 4 - Effect of the 2014 ACA Medicaid Expansions on the probability of working part-time, full-time, or overtime hours

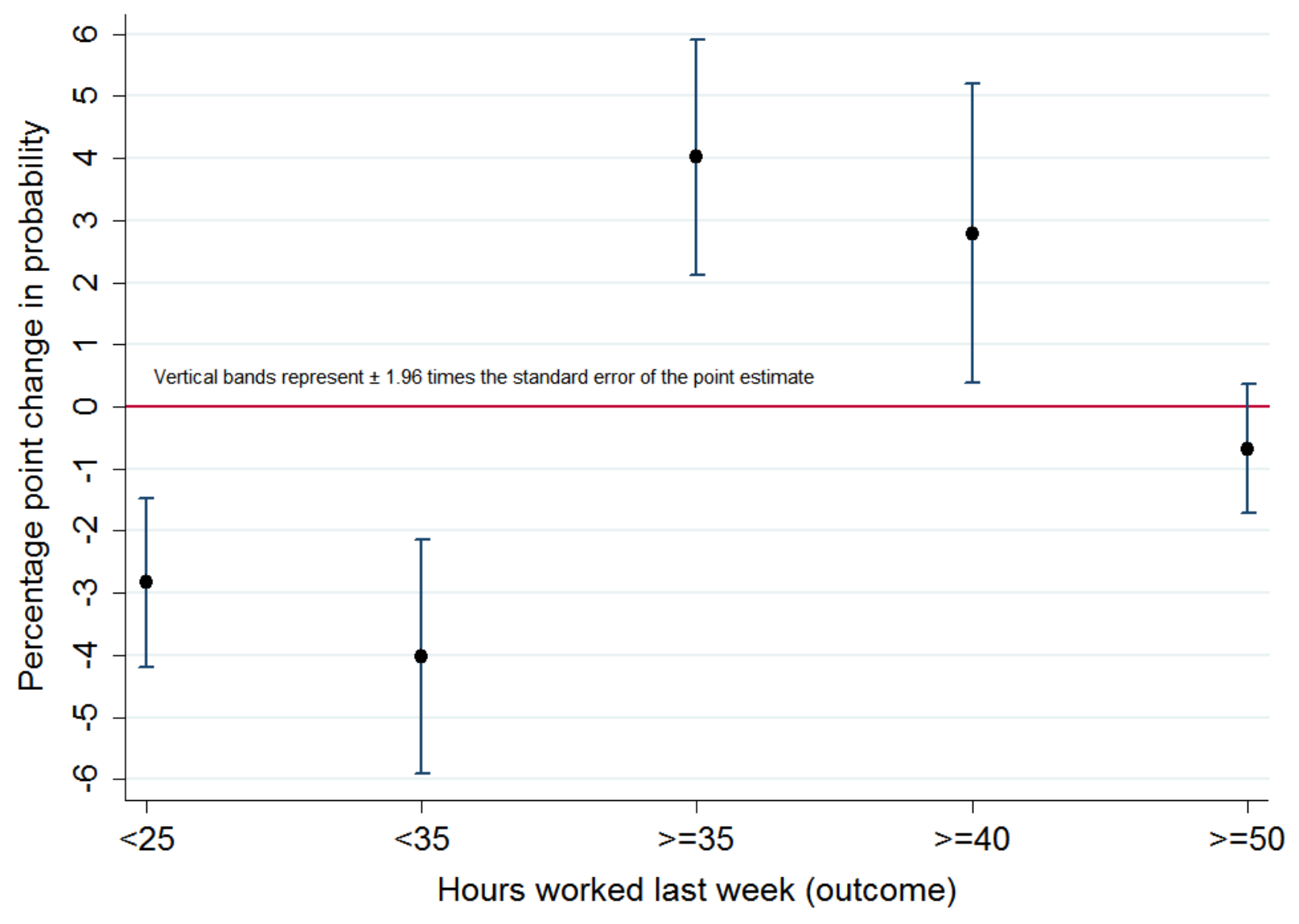




\section{Tables}

Table 1: Effects of the ACA Medicaid expansions on health insurance coverage of low-income adults

\begin{tabular}{|c|c|c|c|}
\hline & Any insurance & Public insurance & Private insurance \\
\hline \multicolumn{4}{|l|}{ Panel A: All } \\
\hline Expand $_{s t}$ & $\begin{array}{c}0.059 * * * \\
(0.008)\end{array}$ & $\begin{array}{c}0.088 * * * \\
(0.009)\end{array}$ & $\begin{array}{c}-0.028 * * * \\
(0.009)\end{array}$ \\
\hline Pre-2014 mean & 0.680 & 0.334 & 0.392 \\
\hline$N$ & $2,055,868$ & $2,055,868$ & $2,055,868$ \\
\hline$R^{2}$ & 0.134 & 0.213 & 0.174 \\
\hline \multicolumn{4}{|l|}{ Panel B: Urban } \\
\hline Expand $_{s t}$ & $\begin{array}{c}0.049 * * * \\
(0.008)\end{array}$ & $\begin{array}{c}0.081 * * * \\
(0.008)\end{array}$ & $\begin{array}{c}-0.032 * * * \\
(0.004)\end{array}$ \\
\hline Pre-2014 mean & 0.673 & 0.323 & 0.393 \\
\hline$N$ & $1,440,665$ & $1,440,665$ & $1,440,665$ \\
\hline$R^{2}$ & 0.147 & 0.214 & 0.175 \\
\hline \multicolumn{4}{|l|}{ Panel C: Rural } \\
\hline Expand $_{s t}$ & $\begin{array}{c}0.098 * * * \\
(0.014)\end{array}$ & $\begin{array}{c}0.119 * * * \\
(0.015)\end{array}$ & $\begin{array}{l}-0.016^{*} \\
(0.008)\end{array}$ \\
\hline Pre-2014 mean & 0.691 & 0.358 & 0.383 \\
\hline$N$ & 322,653 & 322,653 & 322,653 \\
\hline$R^{2}$ & 0.088 & 0.222 & 0.182 \\
\hline
\end{tabular}

Note: Standard errors in parentheses clustered on state. Low-income adults are defined as those with $\$ 35,000$ in total family income or less. Observations from Alaska, Indiana, Louisiana, Michigan, New Hampshire, and Pennsylvania are omitted from all regressions. Regressions include individual controls (indicators for age, race, education, marital status, employed, and immigrant), the state unemployment rate, state fixed effects, and year fixed effects and are weighted using the ACS survey weights.

${ }^{*} p<0.10,{ }^{* *} p<0.05,{ }^{* * *} p<0.01$ 
Table 2: Test for parallel trends in nurse labor market outcomes prior to 2014 expansions

\begin{tabular}{lccc}
\hline & $\log ($ employment $)$ & Hours & Log(hourly wage) \\
\hline Trend $_{t}$ & 0.009 & $0.346^{* *}$ & $0.023^{* *}$ \\
& $(0.008)$ & $(0.133)$ & $(0.010)$ \\
Trend $\left._{t}\right) \times\left(\right.$ Expansion $\left._{s}\right)$ & 0.004 & -0.106 & $-0.012^{*}$ \\
& $(0.011)$ & $(0.095)$ & $(0.006)$ \\
$R^{2}$ & & & \\
$\mathrm{~N}:$ & 0.081 & 0.044 & 0.370 \\
\hline
\end{tabular}

Note: Standard errors in parentheses clustered on state. Trend $_{t}$ is a linear time trend and Expansion E $_{s}$ is an indicator variable equal to one for states that expanded Medicaid in 2014. Observations from Alaska, Indiana, Louisiana, Michigan, Montana, New Hampshire, and Pennsylvania are omitted from all regressions. Employment event study uses data from the 2010-2013 American Community Surveys. Hours event study uses monthly data from the 2010-2013 Current Population Surveys. Earnings event study uses the monthly outgoing rotation group samples from the 2010-2013 Current Population Surveys. The hours and earnings event studies use CPS sample weights and include demographic controls for age, gender, race, and education level as well as the state unemployment rate. The employment event study model includes state and year fixed effects. The hours and earnings event studies include state fixed effects, year fixed effects, and quarter fixed effects. ${ }^{*} p<0.10,{ }^{* *} p<$ $0.05,{ }^{* * *} p<0.01$

Table 3: Effect of ACA Medicaid expansions on nurse employment

\begin{tabular}{lcc}
\hline & $(1)$ & $(2)$ \\
\hline Expand $_{\text {st }}$ & 0.042 & 0.027 \\
& $(0.028)$ & $(0.048)$ \\
Pre-2014 mean & & 10.50 \\
$\mathrm{~N}$ & 10.50 & 264 \\
$R^{2}$ & 264 & 0.397 \\
\hline State fixed effects & 0.254 & Yes \\
Year fixed effects & Yes & Yes \\
State-specific linear trends & Yes & Yes \\
\hline
\end{tabular}

Note: Standard errors in parentheses clustered on state. Observations from Alaska, Indiana, Louisiana, Michigan, Montana, New Hampshire, and Pennsylvania are omitted from all regressions. Data from the 2010-2015

American Community Surveys. 
Table 4: Effect of ACA Medicaid expansions on nurse hours and hourly wage

\begin{tabular}{|c|c|c|c|c|}
\hline & (1) & (2) & (3) & (4) \\
\hline \multicolumn{5}{|l|}{ Panel A: hours } \\
\hline Expand $_{s t}$ & $\begin{array}{l}0.463^{*} \\
(0.234)\end{array}$ & $\begin{array}{c}0.487 * * \\
(0.219)\end{array}$ & $\begin{array}{c}0.553^{* *} \\
(0.214)\end{array}$ & $\begin{array}{c}0.712 * * * \\
(0.264)\end{array}$ \\
\hline Pre-2014 mean: & 36.72 & 36.72 & 36.72 & 36.72 \\
\hline $\mathrm{N}$ & 93,781 & 93,781 & 93,781 & 93,781 \\
\hline$R^{2}$ & 0.015 & 0.043 & 0.043 & 0.044 \\
\hline \multicolumn{5}{|l|}{ Panel B: $\log$ (hourly wage) } \\
\hline Expand $_{s t}$ & $\begin{array}{c}-0.016 \\
(0.018)\end{array}$ & $\begin{array}{l}-0.002 \\
(0.017)\end{array}$ & $\begin{array}{l}-0.002 \\
(0.017)\end{array}$ & $\begin{array}{c}0.020 \\
(0.019)\end{array}$ \\
\hline Pre-2014 mean & 3.298 & 3.298 & 3.298 & 3.298 \\
\hline $\mathrm{N}$ & 15,716 & 15,716 & 15,716 & 15,716 \\
\hline$R^{2}$ & 0.098 & 0.372 & 0.376 & 0.379 \\
\hline State fixed effects & Yes & Yes & Yes & Yes \\
\hline Quarter-of-year fixed effects & Yes & Yes & Yes & Yes \\
\hline Year fixed effects & Yes & Yes & Yes & Yes \\
\hline Demographic controls & No & Yes & Yes & Yes \\
\hline State controls & No & No & Yes & Yes \\
\hline State-specific linear trends & No & No & No & Yes \\
\hline
\end{tabular}

Note: Standard errors in parentheses clustered on state. Observations from Alaska, Indiana, Louisiana, Michigan, Montana, New Hampshire, and Pennsylvania are omitted from all regressions. Hours regression uses monthly data from the 2010-2016 Current Population Surveys. Hourly wage regression uses the monthly outgoing rotation group samples from the 2010-2016 Current Population Surveys.

${ }^{*} p<0.10,{ }^{* *} p<0.05,{ }^{* * *} p<0.01$

Table 5: Effect of ACA Medicaid expansions on nurse hours

\begin{tabular}{lccccc}
\hline & $\begin{array}{c}\text { Less than } 25 \\
\text { hours }\end{array}$ & $\begin{array}{c}\text { Less than } 35 \\
\text { hours }\end{array}$ & $\begin{array}{c}35 \text { hours or } \\
\text { more }\end{array}$ & $\begin{array}{c}40 \text { hours or } \\
\text { more }\end{array}$ & $\begin{array}{c}50 \text { hours or } \\
\text { more }\end{array}$ \\
\hline Expand $_{\text {st }}$ & $-0.028^{* * *}$ & $-0.040^{* * *}$ & $0.040^{* * *}$ & $0.0028^{* *}$ & -0.007 \\
& $(0.007)$ & $(0.010)$ & $(0.010)$ & $(0.012)$ & $(0.005)$ \\
Pre-2014 mean & 0.145 & 0.270 & 0.730 & 0.545 & 0.062 \\
$\mathrm{~N}$ & 93,781 & 93,781 & 93,781 & 93,781 & 93,781 \\
$R^{2}$ & 0.034 & 0.054 & 0.054 & 0.049 & 0.017 \\
\hline
\end{tabular}

Note: Standard errors in parentheses clustered on state. Observations from Alaska, Indiana, Louisiana, Michigan, Montana, New Hampshire, and Pennsylvania are omitted from all regressions. All regressions include individual controls (indicators for age, gender, race, education, immigrant, number of children, and registered nurse occupation), the average yearly state unemployment rate, state fixed effects, quarter-of-year fixed effects, and year fixed effects. Data from the 2010-2016 Current Population Surveys.

${ }^{*} p<0.10,{ }^{* *} p<0.05,{ }^{* * * *} p<0.01$ 
Table 6: Effects of ACA Medicaid expansions on patient ratings of nursing care

\begin{tabular}{lcccc}
\hline Outcome: & $\begin{array}{c}\text { Nurses always } \\
\text { communicated } \\
\text { well }\end{array}$ & $\begin{array}{c}\text { Staff always } \\
\text { responded when } \\
\text { needed }\end{array}$ & $\begin{array}{c}\text { Pain was } \\
\text { always well } \\
\text { controlled }\end{array}$ & $\begin{array}{c}\text { Staff always } \\
\text { explained } \\
\text { medication }\end{array}$ \\
\hline Expand $_{\text {st }}$ & 0.075 & 0.136 & -0.037 & 0.246 \\
& $(0.231)$ & $(0.309)$ & $(0.217)$ & $(0.248)$ \\
Pre-2014 mean & 77.78 & 65.03 & 69.94 & 62.38 \\
N: & 14,946 & 8,640 & 18,330 & 18,312 \\
Number of hospitals & 2,491 & 1,440 & 3,055 & 3,052 \\
$R^{2}$ & 0.184 & 0.103 & 0.024 & 0.121 \\
\hline
\end{tabular}

Note: Standard errors in parentheses clustered on state. Observations from Alaska, Indiana, Louisiana, Michigan, Montana, New Hampshire, and Pennsylvania are omitted from all regressions. Each sample is balanced to remove hospitals that are not in each survey year. Each regression includes hospital fixed effects and year fixed effects. Data from the 2010-2015 Hospital Consumer Assessment of Healthcare Providers Surveys included in the U.S. Centers for Medicare and Medicaid Services Hospital Compare archive. ${ }^{*} p<0.10,{ }^{* *} p<0.05,{ }^{* * *} p<0.01$

Table 7: Effects of ACA Medicaid expansions on hospital infection rates

\begin{tabular}{lcccc}
\hline & $\begin{array}{c}\text { Catheter } \\
\text { associated } \\
\text { urinary tract } \\
\text { infections }\end{array}$ & $\begin{array}{c}\text { Central line } \\
\text { associated } \\
\text { bloodstream } \\
\text { infections }\end{array}$ & $\begin{array}{c}\text { Abdominal } \\
\text { surgical site } \\
\text { infections }\end{array}$ & $\begin{array}{c}\text { Colo-rectal } \\
\text { surgical site } \\
\text { infections }\end{array}$ \\
\hline Expand & $\begin{array}{c}0.006 \\
(0.008)\end{array}$ & $\begin{array}{c}0.019^{* *} \\
(0.008)\end{array}$ & 0.045 & -0.036 \\
Pre-2014 mean & 0.150 & 0.089 & 0.791 & $(0.143)$ \\
N: & 9,820 & 5,890 & 9,252 & 2.632 \\
Number of hospitals & 2,455 & 1,178 & 2,313 & 9,664 \\
$R^{2}$ & 0.054 & 0.009 & 0.002 & 2,416 \\
\hline
\end{tabular}

Note: Standard errors in parentheses clustered on state. Observations from Alaska, Indiana, Louisiana, Michigan, Montana, New Hampshire, and Pennsylvania are omitted from all regressions. Each infection rate sample is balanced to remove hospitals that are not in each survey year. Each regression includes hospital fixed effects and year fixed effects. Data from the 2011-2015 U.S. Centers for Medicare and Medicaid Services Hospital Compare data. Infection data is only available from 2012-2015 for catheter associated urinary tract infections, abdominal surgical site infections, and colo-rectal surgical site infections. ${ }^{*} p<0.10,{ }^{* *} p<0.05,{ }^{* * *} p<0.01$ 
Table 8: Effects of ACA Medicaid expansions on nurse labor market outcomes for urban and rural nurses

\begin{tabular}{lcc}
\hline & Urban & Rural \\
\hline Panel A: employment & & \\
Expand & -0.065 & 0.030 \\
& $(0.096)$ & $(0.091)$ \\
Pre-2014 mean & 9.956 & 9.055 \\
$\mathrm{~N}:$ & 262 & 262 \\
$R^{2}$ & 0.151 & 0.064 \\
\hline Panel B: hours & & \\
\hline Expand & & $1.644^{* * *}$ \\
& $0.389^{*}$ & $(0.586)$ \\
Pre-2014 mean & $(0.207)$ & \\
$\mathrm{N}:$ & & 37.08 \\
$R^{2}$ & 36.65 & 20,433 \\
Panel C: $\log$ (hourly wage) & 73,348 & 0.060 \\
\hline Expand & 0.044 & \\
& & 0.037 \\
& -0.010 & $(0.027)$ \\
Pre-2014 mean & $(0.018)$ & 3.141 \\
$\mathrm{~N}:$ & 3.328 & 3,417 \\
$R^{2}$ & 12,299 & 0.457 \\
\hline
\end{tabular}

Note: Standard errors in parentheses clustered on state. Observations from Alaska, Indiana, Louisiana, Michigan, Montana, New Hampshire, and Pennsylvania are omitted from all regressions Employment regression uses data from the 2010-2015 American Community Surveys. Hours event study uses data from the 2010-2016 Current Population Surveys from 2010-2016. Earnings event study uses the outgoing rotation group samples from the 2010-2016 Current Population Surveys. The hours and wage regressions use CPS sample weights and include demographic controls for age, gender, race, and education level as well as the state unemployment rate. The employment regression includes state and year fixed effects. The hours and wage regressions include state fixed effects, year fixed effects, and quarter fixed effects. ${ }^{*} p<0.10,{ }^{* *} p<0.05,{ }^{* * *} p<0.01$ 
Table 9: Effects of ACA Medicaid expansions on patient ratings of nursing care

\begin{tabular}{|c|c|c|c|c|}
\hline Outcome: & $\begin{array}{c}\text { Nurses always } \\
\text { communicated } \\
\text { well }\end{array}$ & $\begin{array}{l}\text { Staff always } \\
\text { responded } \\
\text { when needed }\end{array}$ & $\begin{array}{c}\text { Pain was } \\
\text { always well } \\
\text { controlled }\end{array}$ & $\begin{array}{l}\text { Staff always } \\
\text { explained } \\
\text { medication }\end{array}$ \\
\hline \multicolumn{5}{|l|}{ Panel A: urban hospitals } \\
\hline Expand $_{\text {st }}$ & $\begin{array}{c}0.245 \\
(0.305)\end{array}$ & $\begin{array}{c}0.097 \\
(0.424)\end{array}$ & $\begin{array}{c}0.315 \\
(0.261)\end{array}$ & $\begin{array}{c}0.148 \\
(0.338)\end{array}$ \\
\hline Pre-2014 mean & 76.42 & 62.44 & 69.00 & 60.78 \\
\hline $\mathrm{N}:$ & 7,894 & 4,780 & 10,095 & 10,091 \\
\hline Number of hospitals & 1,338 & 798 & 1,683 & 1,683 \\
\hline$R^{2}$ & 0.242 & 0.167 & 0.040 & 0.190 \\
\hline \multicolumn{5}{|l|}{ Panel B: rural hospitals } \\
\hline Expand $_{\text {st }}$ & $\begin{array}{c}0.025 \\
(0.209)\end{array}$ & $\begin{array}{c}0.020 \\
(0.417)\end{array}$ & $\begin{array}{c}-0.573 \\
(0.375)\end{array}$ & $\begin{array}{c}0.275 \\
(0.255)\end{array}$ \\
\hline Pre-2014 mean & 79.52 & 68.44 & 71.12 & 64.45 \\
\hline $\mathrm{N}:$ & 7,831 & 3,717 & 7,923 & 7,913 \\
\hline Number of hospitals & 1,436 & 620 & 1,321 & 1,320 \\
\hline$R^{2}$ & 0.114 & 0.055 & 0.015 & 0.074 \\
\hline
\end{tabular}

Note: Standard errors in parentheses clustered on state. Observations from Alaska, Indiana, Louisiana, Michigan, Montana, New Hampshire, and Pennsylvania are omitted from all regressions. Each sample is balanced to remove hospitals that are not in each survey year. Each regression includes hospital fixed effects and year fixed effects. Data from the 2010-2015 Hospital Consumer Assessment of Healthcare Providers Surveys included in the U.S. Centers for Medicare and Medicaid Services Hospital Compare archive. ${ }^{*} p<0.10,{ }^{* *} p<0.05,{ }^{* * *} p<0.01$ 
Table 10: Effects of ACA Medicaid expansions on infection rates in urban and rural hospitals

\begin{tabular}{|c|c|c|c|c|}
\hline & $\begin{array}{c}\text { Catheter } \\
\text { associated } \\
\text { urinary tract } \\
\text { infections }\end{array}$ & $\begin{array}{l}\text { Central line } \\
\text { associated } \\
\text { bloodstream } \\
\text { infections }\end{array}$ & $\begin{array}{l}\text { Abdominal } \\
\text { surgical site } \\
\text { infections }\end{array}$ & $\begin{array}{l}\text { Colo-rectal } \\
\text { surgical site } \\
\text { infections }\end{array}$ \\
\hline \multicolumn{5}{|l|}{ Panel A: urban hospitals } \\
\hline Expand $_{s t}$ & $\begin{array}{c}0.008 \\
(0.011)\end{array}$ & $\begin{array}{c}0.003 \\
(0.006)\end{array}$ & $\begin{array}{l}-0.030 \\
(0.101)\end{array}$ & $\begin{array}{c}0.169 \\
(0.143)\end{array}$ \\
\hline $\begin{array}{l}\mathrm{N}: \\
R^{2}\end{array}$ & $\begin{array}{l}6,125 \\
0.116 \\
\end{array}$ & $\begin{array}{l}3,506 \\
0.011 \\
\end{array}$ & $\begin{array}{l}5,764 \\
0.001 \\
\end{array}$ & $\begin{array}{l}5,984 \\
0.009\end{array}$ \\
\hline \multicolumn{5}{|l|}{ Panel B: rural hospitals } \\
\hline Expand $_{s t}$ & $\begin{array}{c}0.002 \\
(0.010)\end{array}$ & $\begin{array}{c}0.042 * * \\
(0.017)\end{array}$ & $\begin{array}{c}0.107 \\
(0.171)\end{array}$ & $\begin{array}{c}-0.234 \\
(0.305)\end{array}$ \\
\hline $\begin{array}{l}\mathrm{N}: \\
R^{2}\end{array}$ & $\begin{array}{l}3,620 \\
0.014\end{array}$ & $\begin{array}{l}2,190 \\
0.005\end{array}$ & $\begin{array}{l}3,305 \\
0.002 \\
\end{array}$ & $\begin{array}{l}3,497 \\
0.003\end{array}$ \\
\hline
\end{tabular}

Note: Standard errors in parentheses clustered on state. Observations from Alaska, Indiana, Louisiana, Michigan, Montana, New Hampshire, and Pennsylvania are omitted from all regressions. Each infection rate sample is balanced to remove hospitals that are not in each survey year. ${ }^{*} p<0.10,{ }^{* *} p<0.05,{ }^{* * * *} p<0.01$ 
Table 11: Effects of ACA Medicaid expansions on licensed practical/vocational nurses and registered nurses

\begin{tabular}{lccc}
\hline & Log(employment) & Hours & Log(hourly wage) \\
\hline $\begin{array}{l}\text { Panel A: licensed practical/vocational } \\
\text { nurses }\end{array}$ & & & \\
Expand & $0.147^{* *}$ & $0.888^{* *}$ & -0.001 \\
& $(0.060)$ & $(0.418)$ & $(0.033)$ \\
& & & \\
Pre-2014 mean & 6.951 & 36.80 & 2.896 \\
N: & 264 & 14,726 & 2,316 \\
$R^{2}$ & 0.274 & 0.068 & 0.253 \\
\hline Panel B: registered nurses & & & \\
Expand & 0.030 & $0.456^{*}$ & -0.000 \\
& $(0.030)$ & $(0.244)$ & $(0.017)$ \\
Pre-2014 mean & & & \\
N: & 10.31 & 36.70 & 3.370 \\
$R^{2}$ & 264 & 79,055 & 13,400 \\
\hline
\end{tabular}

Note: Standard errors in parentheses clustered at state level. Observations from Alaska, Indiana, Louisiana, Michigan, Montana, New Hampshire, and Pennsylvania are omitted from all regressions. Employment regression uses data from the 2010-2015 American Community Surveys. Hours regression uses monthly data from the 2010-2016 Current Population Surveys. Earnings regression uses the monthly outgoing rotation group samples from the 2010-2016 Current Population Surveys. The hours and earnings event studies use CPS sample weights and include demographic controls for age, gender, race, and education level as well as the state unemployment rate. The employment event study model includes state and year fixed effects. The hours and earnings event studies include state fixed effects, year fixed effects, and quarter fixed effects.

${ }^{*} p<0.10,{ }^{* *} p<0.05,{ }^{* * *} p<0.01$ 
Table 12: Placebo tests for effects of ACA Medicaid expansions on labor market outcomes of unrelated occupations

\begin{tabular}{|c|c|c|c|}
\hline & Log(employment) & Hours & Hourly wage \\
\hline \multicolumn{4}{|c|}{ Panel A: teachers } \\
\hline Expand $_{\text {st }}$ & $\begin{array}{c}-0.003 \\
(0.022)\end{array}$ & $\begin{array}{c}0.307 \\
(0.256)\end{array}$ & $\begin{array}{c}-0.012 \\
(0.010)\end{array}$ \\
\hline $\mathrm{N}:$ & 264 & 140,716 & 27,214 \\
\hline$R^{2}$ & 0.023 & 0.066 & 0.430 \\
\hline \multicolumn{4}{|c|}{ Panel B: architects and engineers } \\
\hline Expand $_{s t}$ & $\begin{array}{c}0.003 \\
(0.032)\end{array}$ & $\begin{array}{c}0.081 \\
(0.214)\end{array}$ & $\begin{array}{c}-0.005 \\
(0.011)\end{array}$ \\
\hline $\mathrm{N}:$ & 264 & 76,887 & 12,870 \\
\hline$R^{2}$ & 0.054 & 0.065 & 0.437 \\
\hline
\end{tabular}

Note: Standard errors in parentheses clustered at state level. Observations from Alaska, Indiana, Louisiana, Michigan, Montana, New Hampshire, and Pennsylvania are omitted from all regressions. Employment regression includes state and year fixed effects and uses data from the 2010-2015 American Community Survey. Hours and hourly wage regressions include controls for single year of age, gender, race, citizenship status, education level, marital status, occupation, the yearly state unemployment rate, state fixed effects, quarter fixed effects, and year fixed effects. Hours and hourly wage regressions use data from the 2010-2016 Current Population Survey.

${ }^{*} p<0.10,{ }^{* *} p<0.05,{ }^{* * * *} p<0.01$ 
Table 13: Sensitivity checks for nurse labor market outcomes

\begin{tabular}{|c|c|c|c|c|c|c|}
\hline & $\begin{array}{c}\text { Main } \\
\text { specification } \\
(1)\end{array}$ & $\begin{array}{c}\text { No sample } \\
\text { weights } \\
\text { (2) }\end{array}$ & $\begin{array}{c}\text { All } \\
\text { industries } \\
\text { (3) }\end{array}$ & $\begin{array}{c}\text { Alternate } \\
\text { treatment } \\
\text { definition } \\
\text { (4) }\end{array}$ & $\begin{array}{c}\text { Drop first } \\
\text { six months } \\
\text { of } 2014 \\
(5)\end{array}$ & $\begin{array}{c}\text { All } \\
\text { states } \\
(6)\end{array}$ \\
\hline \multicolumn{7}{|l|}{$\begin{array}{l}\text { Panel A: } \\
\text { log(employment) }\end{array}$} \\
\hline Expand $_{\text {st }}$ & $\begin{array}{c}0.042 \\
(0.028)\end{array}$ & $\begin{array}{l}- \\
-\end{array}$ & $\begin{array}{l}0.046^{*} \\
(0.027)\end{array}$ & $\begin{array}{c}0.036 \\
(0.029)\end{array}$ & $\begin{array}{l}- \\
-\end{array}$ & $\begin{array}{l}- \\
-\end{array}$ \\
\hline $\mathrm{N}:$ & 264 & - & 264 & 264 & - & - \\
\hline$R^{2}$ & 0.254 & - & 0.287 & 0.252 & - & - \\
\hline \multicolumn{7}{|l|}{ Panel B: hours } \\
\hline Expand $_{s t}$ & $\begin{array}{c}0.553 * * \\
(0.214)\end{array}$ & $\begin{array}{c}0.432 * * \\
(0.206)\end{array}$ & $\begin{array}{c}0.570^{* * * *} \\
(0.201)\end{array}$ & $\begin{array}{c}0.484 * * \\
(0.230)\end{array}$ & $\begin{array}{c}0.608^{* * *} \\
(0.236)\end{array}$ & $\begin{array}{c}0.443 * * \\
(0.210)\end{array}$ \\
\hline $\begin{array}{l}\mathrm{N}: \\
R^{2}\end{array}$ & $\begin{array}{c}93,781 \\
0.043\end{array}$ & $\begin{array}{c}93,781 \\
0.046\end{array}$ & $\begin{array}{c}103,387 \\
0.041\end{array}$ & $\begin{array}{c}93,781 \\
0.043\end{array}$ & $\begin{array}{c}86,960 \\
0.043\end{array}$ & $\begin{array}{c}109,569 \\
0.045\end{array}$ \\
\hline \multicolumn{7}{|l|}{$\begin{array}{l}\text { Panel C: } \\
\text { log(hourly wage) }\end{array}$} \\
\hline Expand $_{\text {st }}$ & $\begin{array}{l}-0.006 \\
(0.017)\end{array}$ & $\begin{array}{l}-0.007 \\
(0.013)\end{array}$ & $\begin{array}{l}-0.007 \\
(0.014)\end{array}$ & $\begin{array}{c}0.025 \\
(0.017)\end{array}$ & $\begin{array}{l}-0.003 \\
(0.019)\end{array}$ & $\begin{array}{l}-0.002 \\
(0.015)\end{array}$ \\
\hline $\begin{array}{l}\mathrm{N}: \\
R^{2}\end{array}$ & 15,990 & 15,990 & 17,544 & 15,990 & 14,797 & 18,299 \\
\hline$R^{2}$ & 0.372 & 0.368 & 0.0353 & 0.372 & 0.372 & 0.366 \\
\hline
\end{tabular}

Note: Standard errors in parentheses clustered at state level. All regressions include controls for single year of age, gender, race, citizenship status, education level, marital status, the yearly state unemployment rate, state fixed effects, quarter fixed effects, and year fixed effects. Observations from Alaska, Indiana, Louisiana, Michigan, Montana, New Hampshire, and Pennsylvania are omitted from regressions in columns 1-5 Column 1 reports the main estimates from column 1 from Table 3 for the employment regression and column 3 of Table 4 for the hours and wage regression. Column 2 re-estimates the main specification without sample weights. Column 3 includes nurses in all industries in the sample. Column 4 includes DE, DC, MA, NY, and VT as ACA Medicaid expansion states. Column 4 re-estimates the main specification, but removes observations from the first six months of 2014. Column 5 drops the first six months of 2014 from the main sample. Column 6 includes all states and recodes the treatment variable include states that expand Medicaid after January 2014. ${ }^{*} p<0.10,{ }^{* * *} p<0.05,{ }^{* * *} p<0.01$ 


\section{Appendix}

\section{A1. Changes in self-assessed health after 2014 ACA Medicaid expansions}

Changes in the type of patients who seek healthcare services can result in changes in quality of care outcomes. Less healthy patients may be more susceptible to acquiring infections or other adverse outcomes which would lower quality of care outcomes even if resources devoted to care were constant or increased. While I do not have measures of patient health, I attempt to identify changes in related measures after the 2014 ACA Medicaid expansions. I use data from the 2010-2016 March Current Population Surveys (March CPS). The March CPS surveys contain important demographic and labor market information such as age, gender, race, education, family size, labor force participation, and income as well as self-reported health measures. I create two indicator variables to measure self-reported health: (1) overall selfreported health - an indicator equal to one for individuals who report their health is "very good" or excellent" and zero otherwise, and (2) has any difficulty - an indicator equal to one for individuals who report having any cognitive difficulty and zero otherwise. A cognitive difficulty includes deafness, blindness, or any difficulty remembering, concentrating, making decisions, performing activities outside the home, or caring for themselves.

I restrict the samples to only include individuals from the treatment and control states described in the main text who are between the ages of 26 and 64. To identify any association between individual demographics or self-reported health and the 2014 Medicaid expansions, I estimate the following equation:

$$
y_{i s t}=\beta_{0}+\beta_{1} \text { Expand }_{s t}+\gamma^{\prime} \boldsymbol{X}_{i s t}+\boldsymbol{\alpha}_{\boldsymbol{s}}+\boldsymbol{\lambda}_{\boldsymbol{t}}+\epsilon_{\text {ist }}
$$

In the equation above, $y_{i s t}$, is an indicator variable for a self-reported health measure or a demographic characteristic. Expand $d_{s t}$ is an indicator variable equal to one in the years 2014 and after for Medicaid expansion states and zero otherwise. $\boldsymbol{X}_{i s t}$ is a vector of individual characteristics that includes indicators for age, gender race, education, marital status, labor force participation, and the yearly average state unemployment rate. I also include state fixed effects, $\boldsymbol{\alpha}_{\boldsymbol{s}}$, and year fixed effects, $\boldsymbol{\lambda}_{\boldsymbol{t}}$. Standard errors are clustered at the state level, and I estimate the regression equation for samples of all adults age 26-64 and adults with total family income of $\$ 35,000$ or less.

Table A1 shows the results for self-reported health measures in the full sample and a sample restricted to low-income individuals. In the full sample, I do not find any statistically significant effects on either self-reported health measure. There is a 1.2 percentage point decrease in reporting excellent or very good health that is statistically significant at the five percent level for the sample of low-income individuals. 
Table A1: Effect of ACA Medicaid Expansions on Self-reported Health

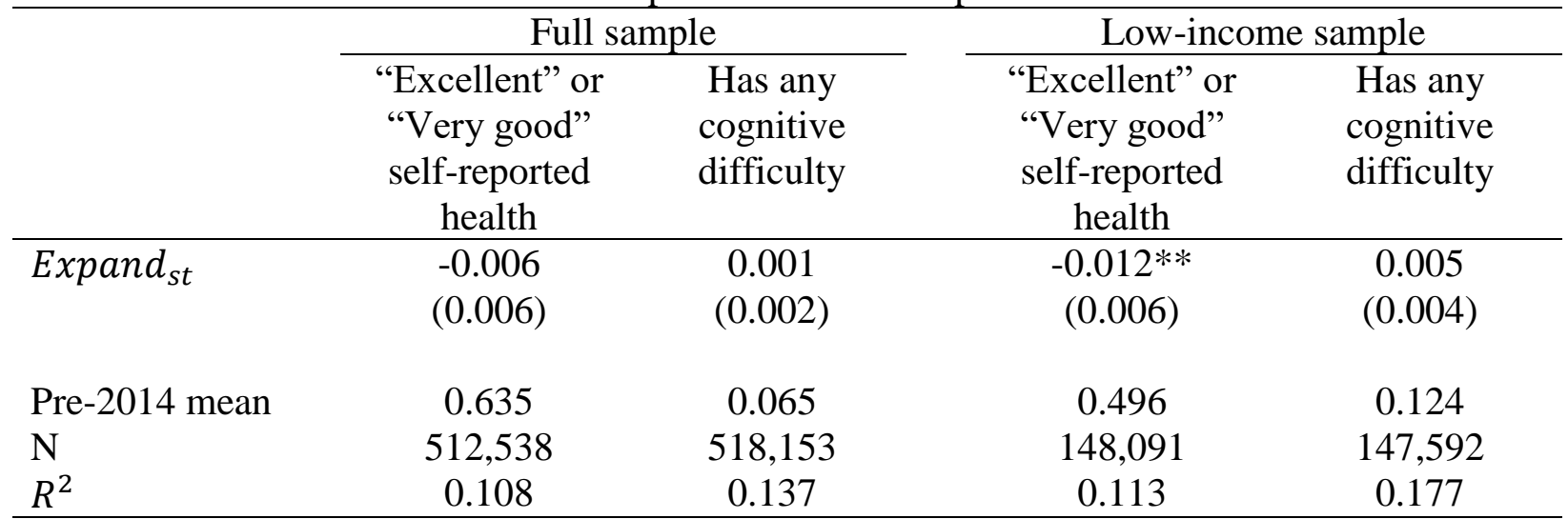

Note: Standard errors in parentheses clustered on state. Samples include adults age 26-64. Low-income adults are defined as those with $\$ 35,000$ in total family income or less. Observations from Alaska, Indiana, Louisiana, Michigan, New Hampshire, and Pennsylvania are omitted from all regressions. Regressions include individual controls (indicators for age, race, education, marital status, immigrant, number of children, labor force participation, and employment status), the state unemployment rate, state fixed effects, and year fixed effects and are weighted using the March CPS survey weights. ${ }^{*} p<0.10,{ }^{* *} p<0.05,{ }^{* * *} p<0.01$ 


\section{A2. Hospital Consumer Assessment of Healthcare Providers and Systems (HCAHPS) survey questions}

Below is a list of the questions from the HCAHPS survey that make up the four composite measures of patient ratings of care. I also describe how the composite measure I use in my analysis is computed by the U.S. CMS. The final public composite measures are adjusted for hospital and patient mix as described in the main text.

Nurse communication composite measures are derived from the three following questions in the HCAHPS survey. A patient must answer each question with "Always" to be included in calculating the percent of patients who rate "nurses always communicate well" in the composite measure.

1. During this hospital stay, how often did nurses treat you with courtesy and respect?

1. Never

2. Sometimes

3. Usually

4. Always

2. During this hospital stay, how often did nurses treat you with listen carefully to you?

1. Never

2. Sometimes

3. Usually

4. Always

3. During this hospital stay, how often did nurses treat you with explain things in a way you could understand?

1. Never

2. Sometimes

3. Usually

4. Always

Responsiveness of hospital staff composite measures are derived from the following two questions in the HCAHPS survey. A patient must answer each question with "Always" to be included in calculating the percent of patients who rate they "always received help as soon as they wanted" in the composite measure.

4. During this hospital stay, after you pressed the call button, how often did you get help as soon as you wanted it?

1. Never

2. Sometimes 
3. Usually

4. Always

5. How often did you get help in getting to the bathroom or in using a bedpan as soon as you wanted?

1. Never

2. Sometimes

3. Usually

4. Always

Pain management composite measure are derived from the three following two questions in the HCAHPS survey. A patient must answer each question with "Always" to be included in calculating the percent of patients who rate "pain was always well controlled" in the composite measure.

6. During this hospital stay, how often did hospital staff talk with you about how much pain you had?

1. Never

2. Sometimes

3. Usually

4. Always

7. During this hospital stay, how often did hospital staff talk with you about how to treat your pain?

1. Never

2. Sometimes

3. Usually

4. Always

Communication about medicines composite measures are derived from the following two questions in the HCAHPS survey. A patient must answer each question with "Always" to be included in calculating the percent of patients who rate "staff always explained medicines" in the composite measure.

8. Before giving you any new medicine, how often did hospital staff yell you what the medicine was for?

1. Never

2. Sometimes

3. Usually 
4. Always

9. Before giving you any new medicine, how often did hospital staff describe possible side effects in a way you could understand?

1. Never

2. Sometimes

3. Usually

4. Always 


\section{A3. Test for differences in commuting patterns after the 2014 ACA Medicaid expansions.}

To test for the possibility that nurse commute patterns change in response to demand shocks from the ACA Medicaid expansions, I use the 2010-2015 ACS data that contains information on both an individual's location of residence and place of work. I combine this with data from the U.S. Department of Agriculture's Economic Research Service that categorizes each Public Use Microdata Area (PUMA) as a metropolitan (urban) or non-metropolitan (rural) area according to population shares in 2003. Thus, I am able to determine if individuals commute from a rural residence to an urban work location based on their respective PUMA codes. I create an indicator variable that equals one for individuals who commute from a rural area to an urban PUMA and zero if the individual resides and works in a rural area. I estimate the following equation for rural-residing nurses:

$$
y_{i s t}=\beta_{0}+\beta_{1} \text { Expand }_{s t}+\gamma^{\prime} \boldsymbol{X}_{i s t}+\boldsymbol{\alpha}_{s}+\boldsymbol{\lambda}_{t}+\epsilon_{i s t}
$$

In equation (A1), $y_{i s t}$ is the previously described indicator variable for a rural-to-urban commuter. $\boldsymbol{X}_{\boldsymbol{i s t}}$ is a vector of demographic indicator variables (single year of age, gender, race, citizenship status, education level, enrolled in school, married, number of children), a registered nurse occupation indicator variable, and the yearly average state unemployment rate. I also include state fixed effects, $\boldsymbol{\alpha}_{s}$, and year fixed effects, $\boldsymbol{\lambda}_{t}$, and cluster the standard errors at the state level.

Table A3 shows the results from this exercise. I do not find any statistically significant effects on rural to urban commuting of nurses due to the ACA Medicaid expansions. The 95 percent confidence interval is to -0.10 to 0.025 , ruling out large increases in rural-to-urban commuting.

Table A3: Effect of ACA Medicaid expansions on commuting patterns of rural-residing nurses

\begin{tabular}{lc}
\hline & Rural to urban commuter \\
\hline Expand $_{s t}$ & -0.038 \\
& $(0.032)$ \\
Pre-2014 mean & 0.376 \\
$\mathrm{~N}$ & 31,797 \\
$R^{2}$ & 0.109 \\
\hline
\end{tabular}

Note: Standard errors in parentheses clustered on state. Observations from Alaska, Indiana, Louisiana, Michigan, Montana, New Hampshire, and Pennsylvania are omitted from the sample. Regression equation includes controls for single year of age, gender, race, citizenship status, education level, enrolled in school, married, number of child, registered nurse occupation, the yearly average state unemployment rate, state fixed effects, and year fixed effects. 